\title{
An Empirical Analysis of Continuing Improvements Following the Implementation of a Performance-Based Compensation Plañ
}

\author{
Rajiv D. Banker ${ }^{a}$, Seok-Young Lee, Gordon Potter ${ }^{\mathrm{c}}$, Dhinu Srinivasan ${ }^{\mathrm{d}}{ }^{\text {** }}$ \\ ${ }^{2}$ School of Management, University of Texas at Dallas, Richardson, TX 75083-0666, USA \\ 'Department of Accounting, Sungshin Women's University, Seoul 136-742, South Korea \\ 'School of Hotel Administration, Comell University, Ithaca, NY 14853-6902, USA \\ ${ }^{d}$ Katz Graduate School of Business, University of Pittsburgh, Pittsburgh, PA 15260, USA \\ Received 14 February 2000; received in revised form 2 April 2001
}

\begin{abstract}
Performance improvements subsequent to the implementation of a pay-for-performance plan can result because more productive employees self-select into the firm (selection effect) and/or because employees allocate effort to become more effective (effort effect). We analyze individual performance data for 3,776 sales employees of a retail firm to evaluate these alternative sources of continuing performance improvement. The incentive plan helps the firm attract and retain more productive sales employees, and motivates these employees to further improve their productivity. In contrast, the less productive sales employees' performance declines before they leave the firm.
\end{abstract}

JEL classification: $\mathrm{D} 8, \mathrm{~J} 33, \mathrm{M} 12, \mathrm{M} 30$

Keywords: Salesforce compensation, Pay-for-performance, Self-selection, Incentive plans, Moral hazard, Productivity improvement.

We gratefully acknowledge helpful comments and suggestions from S.P. Kothari (the editor), Eric Noreen (the referee), Jake Birnberg, John Core, Nandu Nagarajan, and seminar participants at the University of Arizona, Cornell University, University of Memphis, Michigan State University, Syracuse University, University of Pennsylvania, University of Pittsburgh, University of Texas at Dallas, the 1996 Management Accounting Research Conference at Vancouver, the 1997 Annual Meeting of the American Accounting Association at Dallas, the 1998 International Conference on Contemporary Accounting Issues at Taipei, and EAA 2000 - the $23^{\text {rd }}$ Annual Congress of the European Accounting Association at Munich.

*Corresponding author. Tel.: +1-412-648-1513; fax: +1-412-648-1693.

E-mail address: dhinus (a,katz.pitt.edu (D. Srinivasan) 


\section{An Empirical Analysis of Continuing Improvements Following the Implementation of a Performance-Based Compensation Plan}

\section{Introduction}

Many firms link compensation to performance by implementing performance-based incentive programs at every level of the organization [Schlesinger and Heskett, 1991; Coopers and Lybrand, 1992; Buchholz, 1996; McClain, 1998; Pfeffer, 1998; Karr, 1999; Hamilton 1999]. ${ }^{1} \quad$ However, limited evidence exists on the performance impacts of such programs designed for frontline employees [Brown, 1992; Indjejikian, 1999; Murphy, 1999]. While several research studies document that performance-based incentive plans result in performance improvements [Wagner, Rubin and Callahan, 1988; Banker, Lee and Potter, 1996; Lazear, 1999], evidence on factors leading to those improvements is lacking. Also, formal empirical evidence on such plans' multi-period effects on employee selection and retention is lacking [Gerhart and Milkovich, 1992]. Using individual productivity data for 3,776 sales employees for ten quarters following the implementation of a performance-based incentive plan, this study explores alternative sources of continuing performance improvements.

From agency theory perspective, performance-based incentives increase an organization's overall productivity by attracting and retaining more productive employees (selection effect) and/or by inducing employees to increase or to better allocate their effort (effort effect). The selection effect occurs because a performance-based compensation contract can act as a screening device that encourages less productive employees to leave and that motivates more productive employees to join or remain with the firm. However, the impact of this sorting effect on workforce composition may not be instantaneous because employees may not know their own ability with certainty, and, may learn about it only as they receive feedback on their performance. Therefore, progressively higher levels of organizational productivity are expected over time.

\footnotetext{
1 Buck Employees estimate that in 1997, 37\% of Fortune 1,000 companies offered bonus plans to hourly employees, up from $26 \%$ in 1993. Moreover, the bonuses amounted to a larger percentage of salary, $7.8 \%$ in 1997 versus $4.5 \%$ in 1993 [Buchholz, 1996].
} 
The effort effect occurs because a performance-based incentive plan motivates employees to learn more productive ways to perform their tasks. For example, in a selling context, employees can increase their "short-term" routine selling effort or their "long-term" effort in developing customer relations and loyalty that will eventually result in higher future sales. Economic theory suggests that employees with a long multi-period decision horizon, in the presence of performance-based incentives over multiple periods, are likely to devote effort to learn more productive ways of performing their tasks. To the extent employees invest effort in improving their productivity, performance should continue to improve over time (rather than instantaneously) following the introduction of a performance-based incentive plan.

Banker, Lee and Potter (1996) examine a performance-based incentive plan's impact on storewide sales for 15 retail outlets. In addition to finding that plan implementation was associated with an immediate increase in storewide sales, their study documents a continuing improvement (see figure 1). However, the authors could not identify specific causes of continuing storewide performance improvement with store-level data. This paper examines individual level productivity (quarterly sales per hour) data from ten retail stores at Banker, Lee and Potter's (1996) research site that had implemented the incentive plan. The study evaluates whether the continuing increase in sales performance is due to the attraction and retention of more productive employees (selection effect) and/or whether it is due to individual productivity gains driven by the improvements in employee effort (effort effect). Consistent with the predictions of agency theory, the results suggest that both these effects contribute to continuing performance improvements.

Insert figure 1 here

The remainder of this paper is structured as follows. Section 2 describes the research site and the nature of the performance-based incentive plan. Section 3 develops the research hypotheses. Section 4 describes the econometric model and estimation procedures. Section 5 presents the empirical results, and section 6 offers concluding remarks. 


\section{Research site}

The research site is a division of a Fortune 500 company that focuses exclusively on retailing. The division operates a number of retail outlets over a large geographic area. Each retail outlet sells similar merchandise to the general public. Most of the stores are located in or near shopping malls or urban areas. As one of America's largest retailers, its stated selling strategy is to provide customers with exceptional value. Building on its history of excellence in customer service, the division initiated a performance-based incentive plan for sales employees in 1987. The main objectives of this plan are to provide superior customer service beyond the customer's expectations and to attract, retain, and motivate productive employees through increased earnings opportunity. Prior to the implementation of the performance-based incentive plan, sales force compensation was based on fixed hourly wages.

Because division managers were unsure about the precise extent of the incentive plan's impact on sales performance, they phased in the conversion of stores to the plan over a fouryear period. Initially, the division implemented the plan in one store in 1987. By the end of 1990,15 stores out of a total of 34 stores in this geographic region had implemented the plan. Senior managers believed that by holding back stores they would be able to assess the impact of the incentive plan parameters on performance and hence, fine-tune the plan prior to implementing it for the entire salesforce.

The performance-based incentive plan is an add-on bonus program. The incentive plan's key features are as follows: Each week employees get base salaries equal to their hourly rate times hours worked. This base salary is at the same rate as that prior to plan implementation. In addition, an employee earns a cash bonus each quarter if her quarterly sales exceed her pre-specified sales goal. Sales goals for each employee depend on her hourly wage rate, hours worked, her department or merchandise group, and other proprietary factors. An employee's bonus is a percentage of the excess of her actual sales over her pre-specified sales goal in a quarter.

Failure to meet the quarterly goal does not result in a base salary reduction. However, the plan provides for possible termination of an employee if she does not meet her sales goal in two consecutive quarters. If an employee fails to meet her quarterly sales goals, she is subject to the "Below Requirement" process. The intent of this process is to communicate to 
employees whose sales performance is below par that it must be improved within a specific period of time or termination will result. Managers, using a performance status monitor, meet with poor performing employees to inform them of their progress, and to instruct and advise employees on specific actions needed to improve sales performance. Employees do not receive annual merit increases, and promotions are rare. Thus, the bonus program is the only significant reward for high performance. On average, employees' bonuses equal $20 \%$ of base salary. Because these employees have little opportunity for career advancement or other performance-based awards within the firm, this setting is particularly suitable for examining the effects of monetary incentives on individual performance. ${ }^{2}$

Senior managers regarded the incentive plan as a major change for the firm and its salesforce. Recall that prior to plan implementation employees were on straight salary. The firm did not formally track employee productivity and based employees' pay raises on the length of their service experience at the firm. Managers believed that the new incentive plan would motivate many changes in employee behavior, leading to improved customer service and ultimately resulting in higher sales. For instance, managers expected that following the incentive plan employees would begin to build a client base in order to generate repeat sales. Selling efforts consistent with this approach include developing and updating customer address lists, following up on major purchases by customers, writing thank you notes, and contacting customers about upcoming sales and new merchandise. Managers also expected the employees to learn how to sell more effectively. This would occur as employees become more capable of identifying a customer's wants and preferences. Training sessions were held by central administration prior to plan implementation to facilitate employees' transition to this new customer-focused strategy and to introduce the plan to the employees. Moreover, to

\footnotetext{
2 Interviews with managers at our research site indicate that they designed the new incentive plan to have two integral 'carrot and stick' components, a bonus component that rewards superior performance and a penalty component that imposes sanctions for persistent low performance in the form of 'probation' with a threat of possible termination if an employee's performance continues to be below expectation. Our interviews with the human resources manager at our research site reveal that very few employees were terminated because of poor performance. We acknowledge that both these positive and negative incentives can affect an employee's sales productivity. Therefore, we cannot and do not attempt to disentangle these two possible effects on selection, retention and productivity.
} 
encourage employees to be more responsive, plan implementation coincided with empowering them in merchandising and customer discount decisions.

\section{Hypothesis development}

Economic theory suggests that compensation contracts can affect organizational performance by sorting employees and by motivating employees to exert effort. Many firms face a selection problem of having to hire employees without knowing their skill levels. The adverse selection literature examines contracts that take into account employees' different abilities [Spence, 1973; Salop and Salop, 1976]. A performance-based compensation contract results in less productive employees leaving the firm because their expected future wages under the performance-based plan are lower than their prior wages and more productive employees joining the firm because they expect to earn more wages through incentive pay [Milgrom and Roberts, 1992]. Thus, the introduction of the performance-based incentive plan at our research site coupled with the provision for possible termination of employment for poor performance is expected to have two sorting effects. Several experimental studies support these analytical results by documenting that high skilled individuals select performance-based incentive schemes when given a choice between piece rate and fixed pay [Chow, 1983; Waller and Chow, 1985; Dillard and Fisher, 1990; Shields and Waller, 1988]. However, other than a few studies examining chief executive officer (CEO) turnover [Gibbons and Murphy, 1990; Warner, Watts and Wruck, 1988; Weisbach, 1988], little empirical research examines the role of pay-for-performance in attracting and retaining high-performing employees [Milkovich and Wigdor, 1991; Gerhart, Minkoff and Olsen, 1995]. Therefore, we test the following hypotheses:

H1: The sales productivity of existing (pre-plan) employees who remain with the store after the implementation of the performance-based incentive plan is greater than that of both existing employees who leave and new employees who are hired but leave after plan implementation.

H2: The sales productivity of employees hired after the implementation of the performance-based incentive plan is greater than that of existing (pre-plan) employees who leave and new employees who are hired but leave after plan implementation. 
Agency models typically assume that employees have perfect knowledge of their ability. In reality, however, employees might learn about their ability levels only over a period of time based on feedback on their performance. As a result, employee turnover is likely to continue for several periods after plan implementation as employees update their beliefs about their abilities. Therefore, we specify the following hypothesis:

H3: The change in the workforce composition with the more productive employees replacing the less productive employees occurs gradually over time rather than immediately after incentive plan implementation.

As a result, store productivity will continue to increase as the salesforce composition improves over several periods after plan implementation.

When it is not possible to monitor how hard employees are working, performancebased incentive plans help to alleviate potential moral hazard problems by providing incentives to exert more effort or to better allocate effort. The salesforce compensation literature suggests that compared to straight salary a performance-based contract improves a salesperson's performance [Basu, Lal, Srinivasan and Staelin, 1985; Rao, 1990]. In the context where the agent has to choose among multiple effort dimensions, performance improves over time if the new compensation contract provides incentives that favor better ways of performing tasks [Feltham and Xie, 1994; Banker and Thevaranjan, 2000]. Ultimately performance will improve as employees adopt productive activities and eliminate unproductive procedures [Wagner, Rubin and Callahan, 1988]

Prior to plan implementation, at our research site, the fixed wage contract provided employees with little incentive to learn or to exert more than minimal amounts of effort. The new compensation plan provides incentives for employees to exert "short term effort" to effectively close sales and to quickly restock merchandise. In addition, the plan provides incentives to expend more "long term effort" to learn more productive ways to perform selling tasks, to build up a list of loyal well-serviced customers, and to encourage repeat purchases, as employees with a long decision horizon can trade-off the disutility of higher effort against the expected utility of higher future compensation. In contrast, employees with a short decision horizon have less incentive to devote effort to improve their selling skills. Therefore, we test the following hypotheses: 


\section{H4: The sales productivity of continuing employees improves over time.}

\section{H5: The sales productivity of continuing employees improves at a rate greater than that of employees who leave the firm.}

Finally, because the incentive plan induces employees to go beyond their traditional roles, in contrast to the pre-plan fixed wage contract that provided employees with little incentive to learn or to exert more than minimal amounts of effort, the productivity improvement rate for existing (pre-plan) employees resulting from their experience under the incentive plan is likely to be greater than their productivity improvement rate prior to plan implementation. ${ }^{3}$ Therefore, we specify the following hypothesis:

H6: The sales productivity of existing (pre-plan) employees who continue with the store improves at a rate greater than the rate experienced prior to plan implementation.

At our research site the intent of managers was to develop, test and fine-tune a performance-based incentive plan for its salesforce. While we expect that the design of the plan considered the factors discussed above, we do not claim that the incentive plan is optimal nor do we test for its optimality [Jensen and Murphy, 1990]. Moreover, because the firm did not track individual performance data prior to plan implementation, our study is limited to individual productivity changes subsequent to plan implementation.

\section{Model development}

\subsection{Data}

The data consist of 14,651 observations of actual quarterly sales for 3,776 employees from ten retail outlets between August 1989 and January 1992. ${ }^{4}$ Information on employee productivity prior to plan implementation is not available. Although the firm implemented the incentive plan in 15 stores, we limit our analysis to the ten stores for which individual performance information is available at the time of plan implementation. These ten stores are

${ }^{3}$ Because productivity data for pre-plan period are not available, we estimate productivity improvement rates prior to plan implementation based on a regression model discussed in section 4 .

4 Although the firm first implemented the incentive plan in one store in 1987, division headquarters started tracking and collecting individual performance information for plan stores in August 1989. The firm did not collect individual performance information for employees at non-plan stores during the sample period. 
representative of the stores that implemented the incentive plan. Their average sales per hour and size as measured by square footage are not statistically different from those of the five stores that we exclude from our study. In addition to quarterly sales, individual employee information includes hours worked in a quarter, hourly wage rate, store name, merchandise group, and the number of years of service at the store by an employee prior to plan implementation.

To examine the selection and effort effects, we classify each employee in our sample into one of five employee types, and define corresponding indicator variables, as follows:

1) TEMPWORK ( $\mathrm{D}^{\mathrm{TP}}=1,0$ otherwise). Employees who remain with the store for no more than two quarters during the sample period.

2) NEWSTAY ( $D^{\mathrm{NS}}=1,0$ otherwise). Employees who join the store after incentive plan implementation and who remain until the end of our sample period.

3) NEWQUIT $\left(\mathrm{D}^{\mathrm{NQ}}=1,0\right.$ otherwise). Employees who join the store after incentive plan implementation and who leave the store prior to the end of our sample period.

4) OLDQUIT ( $D^{\mathrm{OQ}}=1,0$ otherwise). Employees who are with the store before plan implementation and who leave prior to the end of our sample period.

5) OLDSTAY $\left(D^{\mathrm{OS}}=1,0\right.$ otherwise). Employees who are with the store before plan implementation and who remain until the end of our sample period.

To evaluate the impact of the plan over time, we construct a variable PLANQTR that measures the number of quarters an employee works under the plan. The variable PLANQTR takes on the value one in the employee's first quarter under the plan and increases by one for each quarter completed thereafter. We also include a variable PRIORQTR that measures the number of quarters of an existing (pre-plan, i.e. OLDQUIT and OLDSTAY) employee's experience at the store prior to plan implementation.

We measure an employee's productivity as her average sales per hour (expressed in constant dollars after deflating by CPI) in a quarter (HSALES). The demographic and competitive environment and, to a limited degree, management style are different for each store. Because hourly sales productivity may vary by store due to these factors, we include an indicator variable (denoted by the subscript $\mathbf{s}$ ) for each store. Full-line department stores have 
merchandise groups for children's, men's and women's wear, as well as for accessories. These merchandise categories within a store may require varying degrees of employee effort and store support in the form of advertising and promotional sales. We, therefore, include indicator variables for the 14 merchandise groups (denoted by the subscript $w$ ) that are present in a store. Finally, because the selling season has a large impact on sales productivity, we also include indicator variables for the fiscal quarter (denoted by q).

\subsection{Estimation model}

We model hourly sales of an individual employee $i$ as:

$$
\begin{aligned}
& \text { HSALES }_{i t}=\alpha+v_{i}+\sum_{s=2}^{10} \beta_{s} D_{s i}+\sum_{w=2}^{14} \gamma_{w} D_{w i}+\sum_{q=2}^{4} \xi_{q} D_{q t}+\delta{ }^{N Q} D_{i}^{N Q} \text { PLANQTR }_{i t} \\
& { }_{+}{ }^{\mathrm{NS}} \mathrm{D}_{\mathrm{i}}^{\mathrm{NS}} \mathrm{PLANQTR}_{\mathrm{it}}+\delta^{\mathrm{OQ}} \mathrm{D}_{\mathrm{i}}^{\mathrm{OQ}} \text { PLANQTR }_{\mathrm{it}}+\delta^{\mathrm{OS}} \mathrm{D}_{\mathrm{i}}^{\mathrm{OS}} \mathrm{PLANQTR}_{\mathrm{it}}+\varepsilon_{\mathrm{it}}
\end{aligned}
$$

where,

$$
\begin{aligned}
& v_{i}=\lambda^{T P} D_{i}^{T P}+\lambda^{N Q} D_{i}^{N Q}+\lambda^{N S} D_{i}^{N S}+\lambda{ }_{D_{i}}^{O Q}+\lambda^{O S} D_{i}^{O S} \\
& +\eta{ }^{O Q} D_{i}^{O Q} \text { PRIORQTR }_{i}+\eta^{O S} D_{i}^{O S} \text { PRIORQTR }_{i}+\mu_{i}
\end{aligned}
$$

$i=1 \ldots 3776$, a subscript to denote employee $i$,

$\mathrm{t}=1 \ldots 10$, a subscript to denote the time-period in which the employee works, HSALES $_{\text {it }}=$ employee i's sales per hour (in constant dollars) in time-period $t$, $\mathrm{D}_{\mathrm{si}}=\mathrm{a}$ dummy variable to represent the store $\mathrm{s}$ in which the employee works,

$=1$ if employee $i$ works in store $s(=1 \ldots 10),=0$ otherwise,

$\mathrm{D}_{\mathrm{wi}}=\mathrm{a}$ dummy variable to represent the merchandise group $\mathrm{w}$ in which the employee works, $=1$ if employee $\mathrm{i}$ works in merchandise group $\mathrm{w}(=1 \ldots 14),=0$ otherwise,

$\mathrm{Dqt}=\mathrm{a}$ dummy variable to represent the fiscal quarter $\mathrm{q}(=1 \ldots 4)$,

$=1$ if the time period $\mathrm{t}$ is the same as fiscal quarter $\mathrm{q},=0$ otherwise,

$D_{i}{ }^{T P}=a$ dummy variable that represents a temporary employee,

$=1$ if employee $\mathrm{i}$ is temporary, $=0$ otherwise,

Similarly, $D_{i}{ }^{N Q}, D_{i}{ }^{N S}, D_{i}{ }^{O Q}$, and $D_{i}{ }^{\text {OS }}$ denote NEWQUIT, NEWSTAY, OLDQUIT and OLDSTAY employees, respectively,

PLANQTR = Number of quarters of service by an employee under the plan,

PRIORQTR = Number of quarters of service by an employee prior to the plan,

$\varepsilon_{\mathrm{it}}$ and $\mu_{\mathrm{i}}$ are error terms.

In equation (1), an employee's average hourly sales for a quarter is a function of the store (s), merchandise group (w), fiscal quarter (q), plan experience measured in number of quarters (PLANQTR), an individual specific term $v_{\mathbf{i}}$ and a random error component $\varepsilon_{\mathrm{it}}$. We 
model $v_{i}$ as a function of employee type, past experience (PRIORQTR) and a random individual component $\mu_{\mathrm{i}}$ that represents an individual specific disturbance term, assumed randomly distributed across individuals with mean zero. Substituting equation (2) into (1), we obtain the following model:

$$
\begin{aligned}
& \text { HSALES }_{\mathfrak{t t}}=\alpha+\sum_{\mathrm{s}=2}^{10} \beta_{\mathrm{s}} \mathrm{D}_{\mathrm{si}}+\sum_{\mathrm{w}=2}^{14} \gamma_{\mathrm{w}} \mathrm{D}_{\mathrm{wi}}+\sum_{\mathrm{q}=2}^{4} \xi_{\mathrm{q}} \mathrm{D}_{\mathrm{qt}} \\
& +\lambda^{\mathrm{TP}} \mathrm{D}_{\mathrm{i}}^{\mathrm{TP}}+\lambda^{\mathrm{NQ}} \mathrm{D}_{\mathrm{i}}^{\mathrm{NQ}}+\lambda^{\mathrm{NS}} \mathrm{D}_{\mathrm{i}}^{\mathrm{NS}}+\lambda^{\mathrm{OQ}} \mathrm{D}_{\mathrm{i}}^{\mathrm{OQ}}+\lambda^{\mathrm{OS}} \mathrm{D}_{\mathrm{i}}^{\mathrm{OS}} \\
& +\delta^{N Q} D_{i}^{N Q} \text { PLANQTR it }+\delta^{N S} D_{i}^{N S} \text { PLANQTR it } \\
& +\delta{ }^{O Q} \mathrm{D}_{\mathrm{i}}^{\mathrm{OQ}} \text { PLANQTR it }+\delta{ }_{\mathrm{i}}^{\mathrm{OS}} \mathrm{D}_{\mathrm{PLANQTR}}^{\text {OS }} \text { it } \\
& +\eta^{\text {OQ }} D_{i}^{\text {OQ }} \text { PRIORQTR } i+\eta{ }^{\text {OS }} D_{i}^{\text {OS }} \text { PRIORQTR } i+\mu_{i}+\varepsilon_{i t}
\end{aligned}
$$

We assume:

$$
\begin{aligned}
& E\left[\varepsilon_{i t}\right]=E\left[\mu_{i}\right]=0, E\left[\varepsilon_{i t}^{2}\right]=\sigma_{\varepsilon}^{2}, E\left[\mu_{i}^{2}\right]=\sigma_{\mu}^{2} \\
& E\left[\varepsilon_{i t} \mu_{j}\right]=0 \text { for all } i, j \text { and } t, E\left[\varepsilon_{i t} \varepsilon_{j s}\right]=0 \text { if } i \neq j \text { and } t \neq s, \\
& E\left[\mu_{i} \mu_{j}\right]=0 \text { if } i \neq j .
\end{aligned}
$$

We use the random effects model for estimation purposes because the error component $\mu_{\mathrm{i}}$ is randomly distributed across individuals [Greene, 1993, pp. 469-475]. The appendix outlines the estimation procedure. ${ }^{5}$ An alternative specification is the fixed effects model. The fixed effects model is not feasible given the specification in (3) because many of the variables in the model are linear combinations of the individual dummy variables required in a fixed effect model to represent each individual employee. More importantly, the individual effects for different employees are best modeled as varying around the average due to unidentifiable stochastic factors. This view is consistent with Mundlak (1978) who argues that individual effects should always be treated as random rather than fixed.

\footnotetext{
${ }^{5}$ We also examine all of the coefficients and hypotheses tests presented in this paper using OLS estimates of equation (3), and find the results to be robust. However, the OLS estimates are inefficient as the BreuschPagan (1980) test rejects the null hypothesis that the individual effects are zero $\left(\mathrm{H}_{0}: \sigma_{\mu}{ }^{2}=0\right)$. Empirically, $\hat{\sigma}_{\mu}^{2}$ is approximately $85 \%$ of $\hat{\sigma}_{z}^{2}$.
} 


\subsection{Tests of hypotheses}

The first two hypotheses state that incentive plan implementation results in the attraction and retention of more productive employees. To test these hypotheses, we take into account prior experience (PRIORQTR) of existing (pre-plan) employees and experience under the incentive plan (PLANQTR) for all employees. For instance, the average productivity of NEWSTAY employees at the start of the fifth quarter is $\lambda^{\mathrm{NS}}+4 \delta^{\mathrm{NS}}$. The median PRIORQTR experience for OLDQUIT employees is four quarters. Consequently, the average productivity of a typical OLDQUIT employee after four quarters is $\lambda^{\mathrm{OQ}}+4 \delta^{\mathrm{OQ}}+4 \eta^{\mathrm{OQ}}$ to reflect the productivity improvement of $4 \eta^{\mathrm{OQ}}$ over the four quarters of prior experience. Therefore, ascertaining whether the productivity of NEWSTAY employees at the start of the fifth quarter under the plan is greater than that of OLQUIT employees at the same point in time requires not just the comparison of $\lambda^{\mathrm{NS}}$ and $\lambda^{\mathrm{OQ}}$, but the test of the following inequality: $\lambda^{\mathrm{NS}}+4 \delta^{\mathrm{NS}}>$ $\lambda^{\mathrm{OQ}}+4 \delta^{\mathrm{OQ}}+4 \eta^{\mathrm{OQ}}$. Based on this analysis, we test hypotheses $\mathrm{H} 1$ and $\mathrm{H} 2$ by comparing the productivity of OLDSTAY and NEWSTAY employees to that of OLDQUIT and NEWQUIT employees at various points in time (after 0, 4 and 8 quarters under the plan) after taking into account the impact of prior experience of existing (pre-plan) employees and the impact of plan experience for all employees.

To evaluate Hypothesis $\mathrm{H} 3$ about the changing composition of the workforce, we specify the following model:

$$
\text { PROPORTION (i) })_{s t}=\alpha+\sum_{s=2}^{10} \beta_{s} D_{s}+\sum_{q=2}^{4} \xi_{q} D_{q t}+\gamma_{1} \text { PLANQTR }_{s t}+\gamma_{2} \text { PLANQTR }_{s t}^{2}+e_{s t}
$$

where,

PROPORTION(i $)_{\text {st }}=$ Proportion of an employee type $\mathrm{i}$ in a store's workforce in a quarter $\mathrm{t}$, $\mathrm{i}=$ TEMPWORK, NEWQUIT, NEWSTAY, OLDQUIT and OLDSTAY, $\mathrm{e}_{\mathrm{st}}$ is an error term and other variables are as before.

In this model, the proportions of different employee types in a store's salesforce in quarter $\mathrm{t}$ are regressed against PLANQTR, the time elapsed after plan implementation and PLANQTR ${ }^{2}$, controlling for store-specific factors $\left(D_{s}\right)$ and seasonality $\left(D_{q}\right)$. A positive (negative) $\gamma_{1}$ coefficient of the time variable PLANQTR for an employee type indicates that the proportion of that employee type is increasing (decreasing) over time. Similarly, a positive 
(negative) $\gamma_{2}$ coefficient of the quadratic term PLANQTR ${ }^{2}$ indicates that the proportion of an employee type is changing at an (a) increasing (decreasing) rate.

To evaluate hypothesis $\mathrm{H} 4$ about changes in individual productivity over time we test whether the $\delta$ coefficients in equation (3) are positive. Observe that because PLANQTR is measured as the number of quarters of experience under the plan, $\delta$ represents average productivity improvement per quarter of plan experience. A positive $\delta$ coefficient indicates a productivity improvement over time. To test hypothesis H5 we compare the $\delta$ coefficients of OLDSTAY and NEWSTAY employees with those of OLDQUIT and NEWQUIT employees. Hypothesis H6 states that existing (pre-plan) employees who continue with the store have higher productivity improvement rates under the plan than prior to plan implementation. Because we do not have employee productivity data prior to plan implementation, we infer the average productivity attributable to OLDSTAY and OLDQUIT employees' prior experience based on equation (3). Observe that $\eta$, the average productivity improvement per quarter of prior experience is estimated in the regression based on the cross-sectional variation in hourly sales among existing (pre-plan) employees, whereas the post-plan productivity improvement parameter, $\delta$, for these employees is estimated based on changes in their hourly sales over time after plan implementation. We evaluate Hypothesis H6 by comparing $\eta$ and $\delta$ coefficients for the OLDSTAY and OLQUIT employees.

\section{Results}

\subsection{Preliminary store-level results}

Transition from fixed wages based on tenure and hours worked to a performance-based incentive plan causes changes to the salesforce. These changes evolve slowly as the salesforce responds to the incentives in the new plan. If the performance-based plan is effective in sorting employees by attracting more productive employees and encouraging low performers to leave, then turnover after plan implementation should be higher than turnover before plan implementation. Turnover should gradually subside as the composition of the changed workforce begins to reflect the equilibrium induced by the new performance-based plan. Turnover data are available only after plan implementation. The first two columns of table 1 report empirical analysis of the trend in employee turnover at the ten stores. The parameter 
estimate in the first column, -0.76 , indicates that the proportion of employees leaving the store declined by $0.76 \%$ per quarter from the level experienced immediately on plan implementation. The results for the quadratic model in the second column also suggest that employee turnover at a store declined gradually after plan implementation. This evidence is consistent with the plan inducing a sorting effect that reduces over time as a better matching of the new incentive system and employee type occurs. Company documents also reveal that some managers at the company believed that the new incentive plan was impacting turnover. The following quote from a human resources manager's internal memorandum is consistent with our findings:

"Initially, turnover in plan stores is higher than the non-plan stores as individuals work through changes... Although turnover is high during the first year of the plan, there seems to be a dramatic decrease after the store has been on the plan for one year."

Insert table 1 here

The last two columns display the change in storewide hourly sales productivity (measured as quarterly store sales divided by total employee hours in that quarter) after controlling for economy-wide factors and firm-specific trends in hourly retail sales using the average sales productivity at the 19 control stores that did not implement the incentive plan. The estimated coefficient in the third column relating the average storewide hourly productivity to the number of quarters on the plan suggests that storewide sales productivity increases about $\$ 0.67$ an hour (in constant dollars) on average per quarter. The estimated coefficients for the quadratic model shown in the last column indicate that storewide sales productivity increases at a slightly higher rate on average per quarter. In the analysis that follows, we explore the sources of this continuing improvement.

\subsection{Descriptive statistics}

Table 2 presents descriptive information on the mix of employees for the ten retail outlets used in the study. Comparing the number of observations $(14,651)$ with the number of individuals $(3,776)$ indicates that there are on average about four observations for each employee. However, the number of observations per employee varies by employee type. While we classify only about $17 \%$ of the employees as OLDSTAY, this group represents almost $40 \%$ 
of the observations. Many of the 3,776 employees are temporary (27\%). About 55\% of the permanent employees turn over in these stores in a span of ten quarters.

Insert table 2 here

Table 3 presents summary statistics for the variables used in the study. The mean constant dollar sales per hour (HSALES) ${ }^{6}$ is $\$ 105.14$ and is close to the median (\$99.44). There appears to be a large variation in sales per hour as the standard deviation is $\$ 38.17$, and the range between the first and ninth deciles is $\$ 86.49$. Much of this variation can be explained by the seasonal nature of retail sales. The average sales per hour in the fourth quarter exceeds that of the first quarter by about $\$ 18$ (not reported in the tables). This large difference in quarterly sales has motivated at least one retailer, Macy's, to pare down its commission rate during the fourth quarter (New York Times, 1995). The median employee works about 24.6 hours a week ( $=320.80$ hours per quarter / 13 weeks per quarter). This is typical in the retail industry where full time employees can select from a number of weekly work schedules ranging from 16 to 40 hours. PLANQTR variable indicates that about $50 \%$ of the observations are for employees with at least three quarters of experience under the plan.

Insert table 3 here

Table 4 reports sales per hour in constant dollars (HSALES), number of quarters under the plan (PLANQTR), number of quarters at the store before plan implementation (PRIORQTR), and average hours worked per quarter (HOURS) for each employee type. The average sales per hour for NEWSTAY and OLDSTAY employees are greater than those of TEMPWORK, NEWQUIT and OLDQUIT employees. However, these averages cannot be used to directly compare groups of employees because they do not control for selling season, merchandise category, pre-plan or plan experience, and economy-wide factors such as growth in retail sales. The average quarterly hours worked by TEMPWORK are less than those for any other group. OLDSTAY employees work the most hours. Because all employee types except OLDSTAY have at least one quarter (their first quarter or last quarter) in which they

\footnotetext{
${ }^{6}$ Raw sales per hour are on average $\$ 6-\$ 10$ more than the deflated sales per hour reported in the tables.
} 
may have worked for a fraction of the period, their average quarterly hours are understated. Interestingly, of the employees who are with the firm at the start of the plan, those who remain (OLDSTAY) have 12 (=16-4) more quarters of pre-plan experience (PRIORQTR) than those who quit (OLDQUIT).

Insert table 4 here

\subsection{Regression results}

Table 5 presents the regression results relating employee type, plan experience and quarters of service to sales per hour in constant dollars. Our basic model (model 1) controls for inflation during the sample period because the dependent variable is in constant dollars after deflating by CPI. However, time-series data may be sensitive to temporal changes in retail sales productivity due to other economy-wide, industry- and firm-specific events. Therefore, we include three alternative sales growth indexes (GRWTHINDX) as control variables to reflect changes in hourly sales attributable to changing economic conditions. In model 2 , we examine hourly sales productivity by including a retail sales index (a measure of retail-industry specific inflation) published by the Department of Labor Statistics as a control variable. While this measure controls for economy-wide factors in the retail industry that may affect sales, it does not capture other economy-wide, regional and firm-specific factors that may affect sales over time. Therefore, in model 3 we use as a control variable a sales growth index computed using the total quarterly sales for the 19 control stores that did not implement the plan. In model 4, we employ as a control variable a sales productivity growth index computed as the average quarterly sales per hour for the 19 control stores. Observe that in our research setting, the 19 stores that did not implement the incentive plan provide a natural control because they experience the same impact of inflation as well as other economy-wide, regional and firmspecific factors as the ten stores that we analyze. Thus, the growth indexes used in models 3 and 4 are superior control variables that account for not only inflation but also other factors 
that affect sales. ${ }^{7}$ Because the results of the four models are similar, we limit our discussion to model 4.

Insert table 5 here

\subsubsection{Selection and productivity}

The $\lambda$ coefficients estimate the amount by which a particular employee type's productivity differs from that of OLDSTAY employees before taking into account pre-plan experience. The estimated $\lambda$ coefficients in panel $\mathrm{A}$ of table 5 are all significantly negative indicating that the OLDSTAY employees initially have higher productivity than other types of employees. We present the tests of hypotheses based on model 4 in panel B of table 5. Labels 1.1 through 1.6 in panel B denote tests of hypothesis H1. Test 1.1 compares the productivity of OLDSTAY and OLDQUIT employees at the beginning of the first quarter under the plan holding their prior experience constant. Tests 1.2 and 1.3 compare the productivity of OLDSTAY and OLDQUIT employees after 4 and 8 quarters of plan experience, respectively. In these comparisons, we consider median prior experience of 16 quarters (productivity increases at the rate of $\eta^{\text {os }}$ per quarter) for OLDSTAY employees and four quarters (at the rate of $\eta^{\mathrm{QQ}}$ per quarter) for OLQUIT employees. The tests indicate that at all these points in time, the productivity of OLDSTAY employees exceeds that of OLDQUIT employees. Similarly tests 1.4 through 1.6 reveal that the productivity of OLDSTAY employees exceeds that of NEWQUIT employees after 0,4 and 8 quarters of plan experience.

The first three tests of hypothesis $\mathrm{H} 2$ (labeled as 2.1 through 2.3 ) reveal that NEWSTAY employees' productivity exceeds that of the OLDQUIT employees even after taking into account the prior experience of the OLDQUIT employees. Tests 2.4 through 2.6

\footnotetext{
${ }^{7}$ We also estimate the regression models using raw (undeflated) sales per hour. In this case, model 1 does not control for any trends over time that may affect sales. Model 2 controls for inflation by using the retail-industry specific inflation index as a right hand side variable. Models 3 and 4 implicitly control for inflation because the growth indexes used in these models are based on the 19 control stores that experience the same impact of inflation and other factors as the experimental stores. However, Glejser's (1969) tests based on all the four models using raw sales before deflation by CPI indicate that the residual errors are proportional to CPI (and square of CPI), implying heteroskedasticity in CPI. Therefore, we estimate all the models after deflating by CPI and report results that are based on the deflated models. Glejser's (1969) tests based on the deflated models used in the paper indicate that the residual errors are homoskedastic in CPI. Results based on the undeflated models (not shown in the paper) are qualitatively similar.
} 
indicate that NEWSTAY employees perform significantly better than the NEWQUIT employees at various time periods.

\subsubsection{Selection and turnover}

Figure 2 displays the changes in the proportions of different types of employees over time and provides informal evidence supporting hypothesis $\mathrm{H} 3$ that selection effect occurs gradually over time rather than instantaneously. Observe that the proportion of NEWQUIT employees increases for the first six quarters after plan implementation at about the same ratio as the proportion of NEWSTAY employees. ${ }^{8}$

\section{Insert figure 2 here}

Table 6 presents tests of hypothesis H3. Consistent with figure 2, the coefficients of PLANQTR in both the linear and quadratic models for NEWSTAY employees are positive and that of OLDQUIT employees are negative, and support hypothesis $\mathrm{H} 3$ that the transition from a less productive (OLDQUIT employees) to a more productive (NEWSTAY employees) workforce is gradual. The coefficient of PLANQTR for NEWQUIT employees is positive and the coefficient of PLANQTR ${ }^{2}$ in the quadratic model is negative and consistent with figure 2 , suggesting that the proportion of NEWQUIT employees initially increases but eventually decreases over time. These findings support hypothesis $\mathrm{H} 3$ that some of the new employees (NEWQUIT) who are less productive recognize the limits of their ability only after working for a few quarters and eventually self-select out of the firm. Results for TEMPWORK and OLDSTAY employees suggest that the proportion of temporary employees and existing (preplan) employees who stayed on with a store remains nearly constant. In summary, the results shown in table 6 along with the results discussed earlier document that the performance-based incentive plan induces a gradual selection effect on the composition of the workforce.

Insert table 6 here

\footnotetext{
8 As discussed in footnote 3, our sample period is between August 1989 and January 1992 consisting of a maximum of ten quarters of data for a store. In our figures, we display the results only for eight quarters to document the trend over time. Clearly, the proportions of NEWQUIT and OLDQUIT employees are zero by the end of ten quarters, the length of our sample period.
} 


\subsubsection{Impact of effort effect on productivity}

We evaluate the effect of performance-based incentives in motivating the employees to learn how to sell more effectively by examining the $\delta$ coefficients in panel $\mathrm{A}$ of table 5 . The coefficient estimates shown in panel A reveal that only the NEWSTAY and OLDSTAY employees appear to improve their sales productivity each period under the plan, and the OLDQUIT employees experience a productivity decline before quitting. This finding is consistent with hypothesis $\mathrm{H} 4$ that the effort effect is positive for the continuing employees. Hypothesis H5 asserts that the productivity gains of the continuing employees exceed those of the employees who leave. Panel B shows tests of pair-wise comparisons of the $\delta$ coefficients (labeled as 5.1 through 5.4). Consistent with the point estimates of the $\delta$ coefficients shown in panel $A$, these tests indicate that the OLDSTAY and NEWSTAY employees realize higher productivity gains over time than either the OLDQUIT or NEWQUIT employees.

\subsubsection{Prior experience versus plan experience}

Evaluation of hypothesis $\mathrm{H} 6$ requires a comparison between pre- and post-plan experience effects. The estimated $\eta$ for OLDSTAY and OLDQUIT are positive and statistically significant, indicating that an employee's pre-plan experience has a positive impact on sales productivity. This finding is consistent with the positive link between experience and productivity documented for Navy recruiters by Kostiuk and Follmann (1989) and Asch (1990). A comparison of $\eta$ and $\delta$ coefficients for the OLDSTAY employees indicates that their productivity increases at a significantly more rapid rate after the implementation of the plan ( 0.15 per quarter in the pre-plan period versus 0.31 after implementation). This suggests that the incentive plan motivates the experienced OLDSTAY employees to exert effort to sell more effectively. However, there is no evidence of productivity improvement for the OLDQUIT employees. All four models indicate deteriorating productivity for the OLDQUIT employees after plan implementation.

In addition to testing the hypotheses, we compare the productivity growth rates and the productivity of OLDSTAY and NEWSTAY employees at various points in time, as shown at the bottom of panel $\mathrm{B}$ of table 5. A comparison of $\delta^{\mathrm{NS}}$ and $\delta^{\mathrm{OS}}$ indicates that the productivity improvement rate for NEWSTAY employees is significantly higher than that of OLDSTAY 
employees. A comparison between the OLDSTAY and the NEWSTAY employees suggests that initially the productivity of NEWSTAY employees is lower than that of the OLDSTAY employees. However, the difference in productivity between these two types diminishes with greater experience under the incentive plan because the rate of productivity improvement $\left(\delta^{\mathrm{NS}}\right)$ for the NEWSTAY employees is higher than that for OLDSTAY employees.

Figure 3 portrays the trends in overall productivity for the different types of employees after plan implementation, based on each type's coefficient estimates for model 4 shown in table 5. We use the median values for OLDSTAY and OLDQUIT pre-plan experience, 16 and 4 respectively, to compute the pre-plan experience effect on productivity. The graphs in figure 3 display evidence of both a selection effect and an effort effect. The employees who stay with the store have greater hourly productivity than the employees who quit, indicating a positive selection effect. Interestingly, the figure suggests that productivity of the two employee types who remain with the store seems to converge over time. The two groups of continuing employees also appear to become more effective, as evidenced by their increasing productivity over time. The same is not true for the employees who quit.

Insert figure 3 here

\subsection{Non-linear model}

While figure 3 is based on the assumption that the impact of the effort effect on the sales productivity of different types of employees is linear in plan experience, it is possible that productivity increases at a decreasing rate [Carroll, Lee and Rao, 1986]. To examine a nonlinear relation between effort effects and plan experience, we also include a quadratic term (PLANQTR $^{2}$ ) in our regression models. Panel A of table 7 presents the results based on this alternative specification. The tests of hypotheses, presented in panel B of table 7, are similar to the linear model, but in calculating productivity we also take into account the quadratic term. For example, the productivity of OLDQUIT employees after four quarters of plan experience under the quadratic model is given by $\lambda^{\mathrm{OQ}}+4 \eta^{\mathrm{OQ}}+4 \delta^{\mathrm{OQ}}+16 \theta^{\mathrm{OQ}}$ in contrast to $\lambda^{\mathrm{OQ}}+4 \eta^{\mathrm{QQ}}+$ $4 \delta^{\mathrm{OQ}}$ of the linear model. $16 \theta^{\mathrm{OQ}}$ is the square of plan experience multiplied by its coefficient $\theta^{\mathrm{QQ}}$. Consistent with our earlier findings, the results of tests 1.1 through 1.6, and 2.1 through 
2.6 shown in panel B of table 7 also support hypotheses $\mathrm{H} 1$ and $\mathrm{H} 2$ that the productivity of continuing employees is greater than the productivity of employees who quit. The change in our model specification does not affect tests of hypothesis $\mathrm{H} 3$. The estimated $\delta$ coefficients for the four quadratic models, shown in panel A of table 7, indicate that productivity growth rates under the incentive plan are positive for OLDSTAY and NEWSTAY employees, but the productivity gains occur at a decreasing rate as captured by the negative $\theta$ coefficients. Unlike

Insert table 7 here

the linear model where the $\delta$ coefficients capture the constant productivity growth rate under the plan, the $\delta$ coefficients of the quadratic model do not completely capture the productivity growth rate. Because of the quadratic term, the productivity growth rate is equal to the slope of the quadratic curve $\left(\delta+2^{*}\right.$ PLANQTR $\left.{ }^{*} \theta\right)$ and hence will vary with plan experience. In panel B of table 7, we use a median value of 3 for PLANQTR to test hypotheses H4-H6. ${ }^{9}$ For example, test 4.1 examines if the productivity growth rate of OLDSTAY employees evaluated at the median value of 3 for PLANQTR $\left(\delta^{\mathrm{OS}}+6^{*} \theta^{\mathrm{OS}}\right)$ is greater than 0 . Tests of hypotheses H4-H6, shown in panel B of table 7, are consistent with the results of the linear model. Figure 4 , based on model 4 with quadratic terms, shows the overall productivity for each type of employee over time and, consistent with prior results, supports both selection and effort effect hypotheses.

Insert figure 4 here

\subsection{Examination of an alternative explanation}

The intent of the incentive plan at our research site is to attract and retain productive employees while encouraging less productive employees to leave (selection effect), and to motivate the remaining employees to sell more effectively over time (effort effect). Our empirical results suggest that the incentive plan achieves these objectives. However, because our tests are based on an ex post partitioning of employee types, a survivor bias, that results if

9 Clearly, lower (higher) values of PLANQTR will result in a stronger (weaker) support for these hypotheses because $\theta$ coefficients are negative. 
sales are random occurrences and sorting occurs based on random sales as opposed to ability and effort, may explain our results. For example, some of the least skilled employees are lucky (obtain high sales) and thus stay with the firm until the end of our sample period. Similarly, some of the most skilled employees are unlucky (obtain low sales) and as a result decide to leave the firm. Thus, instead of the incentive plan effectively sorting employees of different ability and effort levels, the documented effects can be explained by the luck of the draw. ${ }^{10}$

The first approach we use to examine this issue is to test whether realized sales are randomly distributed. Our null hypothesis is that the sales productivity of employees is a random variable assuming two levels, lucky sales and unlucky sales, without any employee specific factors driving performance. If realized sales are random occurrences, then an individual's quarterly sales should be independent of her sales in other quarters. Under this assumption sales of each employee will follow a binomial distribution (Mood, Graybill and Boes, 1990, pp. 88-90). Based on the binomial distribution, we can evaluate the null hypothesis by analyzing the time series of each employee's quarterly sales.

To remove shocks in an employee's quarterly sales due to non-employee-specific factors such as store, merchandise, seasonality, and economic factors, we estimate model 4 after omitting employee type, plan experience and pre-plan experience variables to obtain the residual sales. A positive residual denotes lucky sales and a negative residual denotes unlucky sales. Because our hypothesis assumes binary values for the dependent variable, we use the least absolute value (LAV) estimation model. The LAV regression model results in residuals with both an expected mean value of zero and an expected median of zero (Koenker and Bassett, 1978). The null hypothesis is that the probability of a positive residual (lucky sales) in a quarter for any employee regardless of type is equal to 0.5 . If, for example, the sales residuals for an employee in nine out of possible ten quarters are positive, then based on the binomial distribution, we can reject the null hypothesis of random sales for this employee (probability (lucky sales) $=0.5$ ) at a p-value of 0.011 . However, the binomial tests of randomness for each employee (unconditional on the employee type) have very low power

\footnotetext{
${ }^{10}$ We thank the referee for pointing out this possibility.
} 
because of the short length of stay for most employees. ${ }^{11}$ For example, NEWSTAY employees have a median length of stay of six quarters and OLDQUIT employees have a median length of stay of four quarters. Therefore, we analyze the residuals using aggregated data for the employees who stay till the end of our sample period (STAY) and those that quit before the end of our sample period (QUIT), and use the normal distribution because of the large sample size. The results are as follows:

Employee type

STAY

QUIT
Sample probability of a positive sales residual in a quarter p-value of null hypothesis

These results suggest that there are systematic differences in sales between these two groups. For both STAY and QUIT, our tests reject the probability of positive residuals equaling 0.5 . The null hypothesis also implies that the probabilities of positive residuals for STAY and QUIT are equal. Tests indicate that the probability of positive residuals for STAY (NEWSTAY and OLDSTAY employees) is significantly higher than for QUIT (OLDQUIT and NEWQUIT employees). In summary, the results of these tests of quarterly time series of sales residuals indicate that the employees who stay until the end of our sample period are more likely to have systematically higher sales in more quarters than those who quit.

The second approach we take to rule out the alternative explanation of our results is to determine if employees' ability and effort rather than random factors drive sales performance and survival. For the incentive plan to be effective it should attract or retain employees with high selling ability, encourage these employees to exert effort resulting in continuing sales increases and encourage employees without the necessary selling ability and effort to leave. Thus, sales performance and hence survival of employees should be a function of employee ability and effort. We construct a measure of an employee's ability as her first quarterly residual sales based on the modified regression model described earlier. We construct a

${ }^{11}$ Runs or serial correlation tests based on each employee's residual sales (unconditional on the employee type) are other possible approaches to test randomness [Mendenhall, Wackerly, and Scheaffer, 1990, 708-714]. However, these tests also have similar (or worse) limitations than the binomial tests because of the short timeseries of observations for most employees. 
measure of an employee's effort as the change in sales residuals from the first quarter to the second quarter normalized by the sales residual in the first quarter. Observe that these ex ante measures do not depend on ex post classification of employees into STAY and QUIT.

We use observations from an employee's third quarter until the end of sample period or departure to estimate the relation between sales performance and, ability and effort. The estimated regression coefficients based on both OLS and LAV regressions (not shown here) suggest that employee sales are significantly and positively associated with both employee ability and effort. Thus, our measures of ability and effort are positively related to future sales performance. In addition, we analyze the relation between the failure rates (inverse of survival) of employees, and our ability and effort measures. Survivor bias may be present in our results if the tenure of an employee is not related to her ability or effort. Based on the accelerated failure time model (Greene 1993, pp. 721-22), we estimate the failure rate (the probability of an employee who stays until time $t$ quitting in time $t+1$ ) as a function of ability and effort. Based on the actual length of stay for various employees and for a specified underlying distribution such as Weibull or lognormal distribution for the survival function, this model estimates the failure or hazard rate as a function of 'covariates' or other independent variables based on maximum likelihood method. ${ }^{12}$ The estimated coefficients of the ability and effort measures based on this model indicate that the failure rate of employees is negatively and significantly ( $\mathrm{p}=0.01$ ) associated with both ability and effort of employees. ${ }^{13}$ Thus, employee ability and effort help explain the sorting we observe as a result of the incentive plan at our research site. As reported below, STAY had significantly higher levels of ability and effort when compared to QUIT. This finding suggests that continuing productivity gains from incentives are likely to be a function of employee ability and effort.

\footnotetext{
12 The employees who remain until the end of our sample period have right-censored length of stay unlike the people who quit before the sample period. However, the maximum likelihood estimation procedure in SAS handles this problem easily by allowing specification of the censored observations.

${ }^{13}$ We also measure effort as the change in residuals from the $1^{\text {st }}$ quarter till the last quarter of stay. The results are robust to this change of measurement. We estimate the models using Weibull and lognormal distributions, but the results are robust to these specification changes.
} 
Employee type

STAY

QUIT
Mean ability

$-6.16$
Mean effort

$-0.60$

We acknowledge that short time-series of observations for many employees, our measures of employee ability and effort, and the availability of data only during post-plan period constrain our tests. However, because our alternative approaches yield consistent results, we believe that survivor bias arising from random sales is unlikely to explain all of our results. Overall, the results indicate that there are differences in the productivity of the four types of employees and these differences are consistent with predictions from economic theory. Specifically, the incentive plan appears to be successful in attracting and retaining employees who are more productive than those that quit. Moreover, only the employees who remain with the firm show continuing productivity gains. This is consistent with the continuing employees responding to incentives to sell more effectively.

\subsection{Managerial significance}

Regression test results alone are not informative about the relative magnitudes of the selection and effort effects on a store's average hourly sales productivity. Determining their magnitudes requires the consideration of the relative mix of employee types for each quarter under the incentive plan as well as each type's initial productivity and subsequent productivity gains. Therefore, we first compute the average store's employee mix for each plan quarter. Using this empirical distribution of employee types, we compute the average hourly sales productivity for the first eight quarters under the plan by weighting the employee-type productivity estimates (derived from the coefficient estimates for model 4 in table 5) by the proportion of different employee types. Specifically, we denote the overall productivity in period $t$ as $p_{t}=\sum_{i} w_{i t} p_{i t}$, where

$$
\begin{aligned}
& \text { wit = proportion of workforce of employee type } \mathrm{i} \text { in period } \mathrm{t} \text {, } \\
& \mathrm{i}=\text { OLDSTAY, NEWSTAY, OLDQUIT, and NEWQUIT, } \\
& \mathrm{p}_{\mathrm{it}}=\text { sales per hour of employee type } \mathrm{i} \text { in period } \mathrm{t} \text {. }
\end{aligned}
$$

The increase in store productivity from period 0 to period $t$ is: 


$$
\mathrm{p}_{\mathrm{t}}-\mathrm{p}_{0}=\sum_{\mathrm{i}} \mathrm{w}_{\mathrm{it}} \mathrm{p}_{\mathrm{it}}-\sum_{\mathrm{i}} \mathrm{w}_{\mathrm{i} 0} \mathrm{p}_{\mathrm{i} 0}=\sum_{\mathrm{i}}\left(\mathrm{w}_{\mathrm{it}}-\mathrm{w}_{\mathrm{i} 0}\right) \mathrm{p}_{\mathrm{i} 0}+\sum_{\mathrm{i}} \mathrm{w}_{\mathrm{it}}\left(\mathrm{p}_{\mathrm{it}}-\mathrm{p}_{\mathrm{i} 0}\right)
$$

In this expression, the first term is the selection effect and the second term is the effort effect. In figure 5, we further separate the effort effect of the existing (pre-plan) employees $(\mathrm{i}=$ OLDSTAY, OLDQUIT) from that of the new employees ( $\mathrm{i}=$ NEWSTAY, NEWQUTT).

Figure 5 displays estimated average sales per hour for a representative store over an eight-quarter period beginning with the first period on the plan. It is apparent from the figure that both selection and effort effects contribute to the continuing increase in store sales productivity. Little is known about how selection impacts organizational performance. Figure 5 indicates that in our study a large portion of the continuing productivity gains is related to selection. Specifically, in addition to the pure selection effect, the new employee effort effect can be viewed as indirectly related to the selection of new employees.

Insert figure 5 here

\section{Concluding remarks}

Attracting, retaining and motivating effective frontline employees are some of the most critical challenges facing many service firms today. Economic theories predict that performance-based incentives increase an organization's overall productivity by attracting and retaining the more productive employees (selection effect) and/or by inducing employees to increase or to better allocate their effort (effort effect). However, while prior studies document that performance-based pay results in improved performance, empirical evidence on the selection and effort impacts of incentive compensation is lacking, possibly because of lack of objective individual-level performance data [Kostiuk and Follmann, 1989; Asch, 1990]. In this paper, we conduct an analysis of detailed performance data for individual employees to ascertain if these effects explain continuing performance improvements after the implementation of a performance-based incentive plan.

We find evidence that the continuing improvements following the implementation of a performance-based incentive plan are related to these economic theories of behavior. Implementation of the plan leads to the attraction and retention of more productive employees, supporting the hypothesis that a pay-for-performance plan acts as an effective screening device 
by sorting employees by ability. Moreover, the plan motivates the employees remaining with the firm to continually improve their productivity, which suggests that pay-for-performance provides incentives to invest in effort that has long-term performance effects. Thus, the results of this field study support economic theories that analytically demonstrate the importance of both selection and effort effects as drivers of improvements in an organization's performance following the implementation of a pay-for-performance plan. 


\section{References}

Asch, B.J., 1990. "Do incentives matter? The case of navy recruiters," Industrial and Labor Relations Review, Vol. 43, February (Special Issue), 89S-106S.

Banker, R.D., S. Lee, and G. Potter, 1996. "A field study of the impact of a performance-based incentive plan," Journal of Accounting and Economics, Vol. 21, 195-226.

Banker, R.D. and A. Thevaranjan, 2000. "Goal congruence and evaluation of performance measures," Working paper, University of Texas at Dallas, Richardson, TX.

Basu, A.K., R. Lal, B. Srinivasan and R. Staelin, 1985. "Salesforce compensation plans: An agency theoretical perspective," Marketing Science, Vol. 4, Fall, 267-291.

Breusch, T. and A. Pagan, 1980, "The LM Test and Its Applications to Model Specification in Econometrics," Review of Economic Studies, Vol. 47, 239-254.

Brown, C., 1992. "Wage levels and method of pay," RAND Journal of Economics, Vol. 23, No. 3, Autumn, 366-375.

Buchholz, B., 1996. "The bonus isn't reserved for big shots anymore," New York Times, October 27, F10.

Carroll, V.P., Lee, H.L. and A. G. Rao, 1986. "Implications of salesforce productivity heterogeneity and demotivation: a navy recruiter case study," Management Science, Vol. 32, No. 11 November, 1371-1388.

Chow, C., 1983. "The effects of job standard tightness and compensation scheme on performance: An exploration of linkages," The Accounting Review, October, 667-685.

Coopers and Lybrand, 1992. "Editor's page: compensation," Stores, August, 6.

Dillard, J. F. and Fisher, J. G., 1990. "Compensation schemes, skill level and task performance: An experimental examination," Decision Sciences, 121-137.

Feltham, G. and J. Xie, 1994, "Performance measure congruity and diversity in multi-task principal/agent relations," The Accounting Review, July, 429-453.

Gerhart, B. and G. Milkovich, 1992. "Employee compensation: Research and practices," Handbook of Industrial and Organizational Psychological, 2nd Edition, Consulting Psychologists Press, Inc., Palo Alto, CA.

Gerhart,B., H.B. Minkoff and R.N. Olsen, 1995. "Employee compensation: theory, practice and evidence," Handbook of Human Resource Management, Blackwell Business.

Gibbons, R. and K..J. Murphy, 1990. "Relative performance evaluation for chief executive officers," Industrial and Labor Relations Review, Vol. 43, February (Special issue), 30S-51S.

Glejser, H., 1969. "A New Test for Heteroskedasticity," Journal of the American Statistical Association, Vol. 64, 316-323. 
Greene, W., 1993. Econometric analysis, Macmillan Publishing Company.

Hamilton, D.P., 1999. "H-P chief shuffles top roles, says server sales may pinch net," Wall Street Journal, October 4, A4.

Indjejikian, R.J., 1999. Performance evaluation and compensation research: an agency perspective," Accounting Horizons, Vol. 13 No. 2, June, 147-157.

Jensen, M.C. and K.J. Murphy, 1990. "Performance pay and top-management incentives," Journal of Political Economy, Vol.98, No. 2, 225-264.

Karr, A.R., 1999. "Work week: A special news report about life on the job -- and trends taking shape there," Wall Street Journal, April 6, Al

Koenkar, R. and Bassett, Jr. G., 1978, "Regression Quantiles," Econometrica, Vol. 46, No. 1, 3350.

Kostiuk, P.F. and D.A. Follmann, 1989. "Leaming curves, personal characteristics, and job performance," Journal of Labor Economics, Vol. 7, No. 2, 129-146.

Lazear, E.P., 1999. "Performance pay and productivity," Working paper, National Bureau of Economic Research.

McClain, D.L., 1998. "Tricks for varying the pay to motivate the ranks," New York Times, November 15, BU5.

Mendenhall, W., Wackerly, D.D., and Scheaffer, R.L., 1990. Mathematical Statistics with Applications, Duxbury Press, Belmont, CA.

Milgrom, P. and J. Roberts, 1992. Economics, Organization and Management, Prentice Hall, Englewood Cliffs, NJ.

Milkovich, G.T. and A.K. Wigdor, 1991. Pay for performance: Evaluating performance appraisal and merit pay, National Research Council, National Academy Press, Washington, D.C.

Mood, A.M., Graybill, F.A., and Boes, D.C., 1990, Introduction to the Theory of Statistics, McGraw-Hill, New York.

Mundlak, Y, 1978. "On the pooling of time-series and cross sectional data," Econometrics, 46, 6986.

Murphy, K.J., 1999. "Executive compensation," Handbook of Labor Economics (3B), North Holland, Amsterdam.

New York Times, 1995. Macy's marks down some employees' holiday sales commissions, December 15, C1-C4.

Pfeffer, J., 1998. "Six dangerous myths about pay," Harvard Business Review, May/June, 109-119. 
Rao, R.C., 1990. "Compensating heterogeneous salesforces: Some explicit solutions," Marketing Science, 9, 319-341.

Salop, J. and S. Salop, 1976. "Self-selection and turnover in the labor market," Quarterly Journal of Economics, November, 617-627.

Schlesinger, L.A. and J.L. Heskett, 1991. "The service-driven service company," Harvard Business Review, September-October b, 71-81.

Shields, M.D. and Waller, W., 1988. "A behavioral study of accounting variables in performanceincentive contracts," Accounting, Organizations and Society, 581-594

Spence, M., 1973. "Informational aspects of market structure: An introduction," Quarterly Journal of Economics, November, 591-597.

Wagner, J.A., P.A. Rubin, and T.J. Callahan, 1988. "Incentive payment and non-managerial productivity: An interrupted time series analysis of magnitude and trend," Organizational Behavior and Human Decision Processes, Vol. 42, 47-74.

Waller, W.S. and C.W. Chow, 1985. "The self-selection and effort effects of standard-based employment contracts: A framework and some empirical evidence," The Accounting Review, July, 458-476.

Warner, J.B., R.L. Watts and K.H. Wruck, 1988. "Stock prices, event prediction, and event studies: An examination of top management changes," Journal of Financial Economics, Vol. 20, No. 1/2, January/March, 461-492.

Weisbach, M.S., 1988. "Outside directors and CEO turnover," Journal of Financial Economics, Vol. 20, No. 1/2, January/March, 431-460. 


\section{Appendix}

\section{Estimation of Random Effects Model}

We estimate parameters and their standard errors as follows. We first estimate equation (3) using OLS. Using the errors, $e_{1}$, from (3) we obtain the sum of the variances of the random error and individual component based on the following asymptotic relation:

$$
\frac{\text { PLIMe }_{1}^{\prime} \mathrm{e}_{1}}{\mathrm{nT}}=\sigma_{\varepsilon}^{2}+\sigma_{\mu}^{2}
$$

Next, we compute the means by individual for the variables in (3). An OLS regression of these means provides the error terms, $e_{2}$, which have the following property:

$$
\frac{\mathrm{e}_{2}^{\prime} \mathrm{e}_{2}}{\mathrm{n}-\mathrm{k}}=\frac{\sigma_{\varepsilon}^{2}}{\mathrm{~T}}+\sigma_{\mu}^{2}
$$

Since $\mathrm{T}$ is not a constant across groups, we replace it with

$$
T^{*}=\frac{1}{n}\left(\sum_{i=1}^{n} \frac{1}{T_{i}}\right)
$$

Using equations (A1), (A2) and (A3), we compute estimates for $\sigma_{\varepsilon}^{2}$ and $\sigma_{\mu}^{2}$.

The next step in the estimation requires the transformation of all of the variables in equation

(3) as follows:

$$
Y_{i t}^{*}=Y_{i t}-\theta \bar{Y}_{i} \text {, and } X_{j i t}^{*}=X_{j i t}-\theta \bar{X}_{j i}
$$

where $\theta$ is computed as:

$$
\theta=1-\frac{\sigma_{\mathrm{e}}}{\left(\mathrm{T} \sigma_{\mu}^{2}+\sigma_{\varepsilon}^{2}\right)^{\frac{1}{2}}}
$$

We re-estimate equation (3) using OLS with these transformed variables to obtain consistent estimates for the parameters in (3) and their standard errors. 


\section{Table 1}

\section{Regression Results Relating Plan Experience to Storewide Performance Measures}

( $\mathrm{p}$-values in parentheses, $\mathrm{n}=83$ store-quarters)

$$
\begin{gathered}
\text { TURNOVER }_{s t}=\alpha+\sum_{s=2}^{10} \beta_{s} D_{s}+\sum_{q=2}^{4} \xi_{q} D_{q t}+\gamma_{1} \text { PLANQTR }_{s t}+\gamma_{2} \text { PLANQTR }_{s t}^{2}+e_{s t} \\
\text { HSALES }_{s t}=\alpha+\sum_{s=2}^{10} \beta_{s} D_{s}+\sum_{q=2}^{4} \xi_{q} D_{q t}+\gamma_{1} \text { PLANQTR }_{s t}+\gamma_{2} \text { PLANQTR }_{s t}^{2}+\zeta \text { SRWTHINDX }_{t}+e_{s t}
\end{gathered}
$$

\begin{tabular}{|c|c|c|c|c|}
\hline $\begin{array}{r}\text { Dependent } \\
\text { Variable }\end{array}$ & \multicolumn{2}{|c|}{ TURNOVER } & \multicolumn{2}{|c|}{ HSALES } \\
\hline PLANQTR & $\begin{array}{c}-0.76^{* *} \\
(0.01)\end{array}$ & $\begin{array}{c}-1.96^{* *} \\
(0.01)\end{array}$ & $\begin{array}{l}0.67^{*} \\
(0.03)\end{array}$ & $\begin{array}{l}1.53^{*} \\
(0.05)\end{array}$ \\
\hline PLANQTR $^{2}$ & - & $\begin{array}{l}0.11 \\
(0.09)\end{array}$ & - & $\begin{array}{l}-0.08 \\
(0.16)\end{array}$ \\
\hline GRWTHINDX & - & - & $\begin{array}{l}30.05^{*} \\
(0.05)\end{array}$ & $\begin{array}{l}29.96^{*} \\
(0.05)\end{array}$ \\
\hline $\mathrm{p}($ model $)$ & 0.01 & 0.01 & 0.01 & 0.01 \\
\hline Adjusted $\mathrm{R}^{2}$ & 0.29 & 0.31 & 0.89 & 0.89 \\
\hline
\end{tabular}

TURNOVER $_{s t}=$ Percent of a store's permanent employees who quit in a quarter,

HSALES $_{\mathbf{s t}}=$ Storewide quarterly sales divided by storewide selling hours in a quarter,

GRWTHINDX $_{\mathrm{t}}=$ Storewide quarterly sales divided by storewide selling hours in a quarter for the 19 control stores,

PLANQTR $_{\mathrm{st}}=$ Number of quarters of a store under the incentive plan,

$\mathrm{D}_{\mathrm{s}} \quad=$ a dummy variable to represent the store $\mathrm{s}(=1 \ldots 10)$,

$\mathrm{D}_{\mathrm{qt}}=\mathrm{a}$ dummy variable to represent the fiscal quarter $\mathrm{q}(=1 \ldots 4)$,

$=1$ if the time period $t$ is the same as fiscal quarter $q,=0$ otherwise,

**Indicates significant at $1 \%$ level,

*Indicates significant at $5 \%$ level. 
Table 2

\section{Composition of Salesforce}

\begin{tabular}{|l|c|c|c|c|}
\hline \multirow{2}{*}{ Type } & \multicolumn{2}{|c|}{ Employees } & \multicolumn{2}{c|}{ Employee-Quarters } \\
\cline { 2 - 5 } TEMPWORK & Number & Proportion & Number & Proportion \\
NEWQUTT & 1,042 & $27.60 \%$ & 1,286 & $8.78 \%$ \\
NEWSTAY & 460 & $12.18 \%$ & 1,648 & $11.25 \%$ \\
OLDQUIT & 581 & $15.39 \%$ & 2,378 & $16.23 \%$ \\
OLDSTAY & 1,055 & $27.94 \%$ & 3,692 & $25.20 \%$ \\
\hline Total & 638 & $16.89 \%$ & 5,647 & $38.54 \%$ \\
\hline
\end{tabular}

TEMPWORK $\left(D^{\text {TP }}\right)=$ An employee who remains with the store for no more than two quarters during the sample period,

NEWQUIT $\left(D^{\mathrm{NQ}}\right) \quad=$ An employee who joins the store after incentive plan implementation and who leaves the store prior to the end of our sample period,

NEWSTAY $\left(D^{\mathrm{NS}}\right) \quad=$ An employee who joins the store after incentive plan implementation and who remains until the end of our sample period,

OLDQUIT $\left(D^{\mathrm{QQ}}\right)=$ An employee who is with the store before plan implementation and who leaves prior to the end of our sample period,

OLDSTAY $\left(\mathrm{D}^{\mathrm{OS}}\right) \quad=$ An employee who is with the store before plan implementation and who remains until the end of our sample period,

$\mathrm{D}_{\mathrm{i}}^{\mathrm{TP}}=\mathbf{a}$ dummy variable that represents a temporary employee,

$=1$ if employee $\mathrm{i}$ is temporary, $=0$ otherwise,

Similarly, $\mathrm{D}_{\mathrm{i}}^{\mathrm{NQ}}, \mathrm{D}_{\mathrm{i}}^{\mathrm{NS}}, \mathrm{D}_{\mathrm{i}}^{\mathrm{OQ}}$, and $\mathrm{D}_{\mathrm{i}}^{\mathrm{OS}}$ denote NEWQUIT, NEWSTAY, OLDQUIT, and OLDSTAY employees, respectively. 


\section{Table 3}

Descriptive Statistics

$$
(n=14,651 \text { employee-quarters })
$$

\begin{tabular}{|l|c|c|c|c|c|}
\hline Variables & Mean & $\begin{array}{c}\text { Standard } \\
\text { Deviation }\end{array}$ & $\begin{array}{c}\text { 10th } \\
\text { Percentile }\end{array}$ & Median & $\begin{array}{c}\text { 90th } \\
\text { Percentile }\end{array}$ \\
\hline HSALES & $\$ 105.14$ & $\$ 38.17$ & $\$ 64.34$ & $\$ 99.44$ & $\$ 150.83$ \\
HOURS & 310.01 & 123.68 & 134.30 & 320.80 & 464.10 \\
PLANQTR & 3 & 3 & 1 & 3 & 8 \\
PRIORQTR & 14.74 & 25.59 & 0 & 4 & 48 \\
\hline
\end{tabular}

HSALES = An employee's sales per hour (in constant dollars),

HOURS $=$ Hours worked by an employee in a fiscal quarter,

PLANQTR = Number of quarters of service by an employee under the incentive plan,

PRIORQTR = Number of quarters of service by an employee prior to the incentive plan. 


\section{Table 4}

\section{Information by Employee Type}

(Means with medians in parentheses, $\mathrm{n}=3,776$ employees)

\begin{tabular}{|c|c|c|c|c|c|}
\hline $\begin{array}{c}\text { Type } \\
\text { Variable }\end{array}$ & TEMPWORK & NEWQUIT & NEWSTAY & OLDQUIT & OLDSTAY \\
\hline HSALES & $\begin{array}{l}\$ 98.75 \\
(94.25)\end{array}$ & $\begin{array}{l}\$ 91.27 \\
(87.61)\end{array}$ & $\begin{array}{r}\$ 103.93 \\
(99.44)\end{array}$ & $\begin{array}{l}\$ 99.26 \\
(95.90)\end{array}$ & $\begin{array}{l}\$ 114.99 \\
(107.66)\end{array}$ \\
\hline HOURS & $\begin{array}{c}192.60 \\
(169.80)\end{array}$ & $\begin{array}{c}280.90 \\
(272.10)\end{array}$ & $\begin{array}{c}329.30 \\
(350.70)\end{array}$ & $\begin{array}{c}303.00 \\
(302.80)\end{array}$ & $\begin{array}{c}341.70 \\
(357.60)\end{array}$ \\
\hline PLANQTR & $\begin{array}{l}1.41 \\
(1)\end{array}$ & $\begin{array}{l}3.56 \\
(3)\end{array}$ & $\begin{array}{l}5.60 \\
(6)\end{array}$ & $\begin{array}{l}3.88 \\
(4)\end{array}$ & $\begin{array}{l}9.14 \\
(10)\end{array}$ \\
\hline PRIORQTR & - & - & - & $\begin{array}{l}12.98 \\
(4)\end{array}$ & $\begin{array}{l}29.76 \\
(16)\end{array}$ \\
\hline
\end{tabular}

See tables 2 and 3 for variable definitions. 


\section{Table 5}

Regression Results for Random Effects Model

( $\mathrm{p}$-values in parentheses, $\mathrm{n}=14,651$ employee-quarters)

$$
\begin{aligned}
& \text { HSALES }_{i t}=\alpha+\sum_{s=2}^{10} \beta_{s} D_{s i}+\sum_{w=2}^{14} \gamma_{w} D_{w i}+\sum_{q=2}^{4} \xi_{q} D_{q t}+\zeta \text { GRWTHINDX } t+\lambda^{T P} D_{i}^{T P}+\lambda^{N Q} D_{i}^{N Q}+\lambda^{N S} D_{i}^{N S} \\
& +\lambda^{O Q} D_{i}^{O Q}+\delta^{N Q} D_{i}^{N Q} P_{\text {PLANQTR }}{ }_{i t}+\delta^{N S} D_{i}^{N S} \text { PLANQTR }_{i t}+\delta^{O Q} D_{i}^{O Q} \text { PLANQTR }_{i t} \\
& +\delta^{O S} D_{i}^{O S} \text { PLANQTR }_{i t}+\eta^{O Q} D_{i}^{O Q} \text { PRIORQTR }_{i}+\eta^{O S} D_{i} \text { OS }_{\text {PRIORQTR }}{ }_{i}+\mu_{i}+\varepsilon_{i t}
\end{aligned}
$$

\begin{tabular}{|c|c|c|c|c|c|}
\hline \multicolumn{6}{|c|}{ Panel A: Parameter Estimates } \\
\hline \multirow[b]{2}{*}{ Variable } & \multirow[b]{2}{*}{ Coefficient } & \multicolumn{4}{|c|}{ Coefficient Estimates } \\
\hline & & Model 1 & Model 2 & Model 3 & Model 4 \\
\hline$D^{T P}$ & $\lambda^{T P}$ & $\begin{array}{l}-7.84^{* *} \\
(0.01)\end{array}$ & $\begin{array}{l}-8.39^{* *} \\
(0.01)\end{array}$ & $\begin{array}{l}-7.66^{* *} \\
(0.01)\end{array}$ & $\begin{array}{l}-8.77^{* *} \\
(0.01)\end{array}$ \\
\hline$D^{N Q}$ & $\lambda^{N Q}$ & $\begin{array}{l}-9.98 * * \\
(0.01)\end{array}$ & $\begin{array}{c}-10.31^{* *} \\
(0.01)\end{array}$ & $\begin{array}{l}-9.88^{* *} \\
(0.01)\end{array}$ & $\begin{array}{c}-10.44^{* *} \\
(0.01)\end{array}$ \\
\hline$D^{N S}$ & $\lambda^{N S}$ & $\begin{array}{l}-5.10^{* *} \\
(0.01)\end{array}$ & $\begin{array}{l}-5.56^{* *} \\
(0.01)\end{array}$ & $\begin{array}{l}-4.95^{* *} \\
(0.01)\end{array}$ & $\begin{array}{l}-5.82^{* *} \\
(0.01)\end{array}$ \\
\hline$D^{O Q}$ & $\lambda^{O Q}$ & $\begin{array}{l}-9.19^{* *} \\
(0.01)\end{array}$ & $\begin{array}{l}-9.12^{* *} \\
(0.01)\end{array}$ & $\begin{array}{l}-9.19^{* *} \\
(0.01)\end{array}$ & $\begin{array}{l}-9.13^{* *} \\
(0.01)\end{array}$ \\
\hline$D^{N Q}$ PLANQTR & $\delta^{N Q}$ & $\begin{array}{l}-0.24 \\
(0.27)\end{array}$ & $\begin{array}{l}-0.30 \\
(0.23)\end{array}$ & $\begin{array}{l}-0.20 \\
(0.31)\end{array}$ & $\begin{array}{l}-0.33 \\
(0.20)\end{array}$ \\
\hline$D^{N S}$ PLANQTR & $\delta^{N S}$ & $\begin{array}{l}1.28^{* *} \\
(0.01)\end{array}$ & $\begin{array}{l}1.21^{* *} \\
(0.01)\end{array}$ & $\begin{array}{l}1.32^{* *} \\
(0.01)\end{array}$ & $\begin{array}{l}1.14^{* *} \\
(0.01)\end{array}$ \\
\hline$D^{O Q}$ PLANQTR & $\delta^{O Q}$ & $\begin{array}{l}-0.49^{*} \\
(0.02)\end{array}$ & $\begin{array}{l}-0.61^{*} \\
(0.02)\end{array}$ & $\begin{array}{l}-0.45^{*} \\
(0.03)\end{array}$ & $\begin{array}{l}-0.67^{* *} \\
(0.01)\end{array}$ \\
\hline$D^{O S}$ PLANQTR & $\delta^{o S}$ & $\begin{array}{l}0.47^{* *} \\
(0.01)\end{array}$ & $\begin{array}{r}0.37^{*} \\
(0.02)\end{array}$ & $\begin{array}{l}0.51^{* *} \\
(0.01)\end{array}$ & $\begin{array}{l}0.31 * * \\
(0.01)\end{array}$ \\
\hline$D^{O Q}$ PRIORQTR & $\eta^{O Q}$ & $\begin{array}{l}0.11^{* *} \\
(0.01)\end{array}$ & $\begin{array}{l}0.11^{* *} \\
(0.01)\end{array}$ & $\begin{array}{l}0.11^{* *} \\
(0.01)\end{array}$ & $\begin{array}{l}0.11^{* *} \\
(0.01)\end{array}$ \\
\hline$D^{O S}$ PRIORQTR & $\eta^{o s}$ & $\begin{array}{l}0.15^{* *} \\
(0.01)\end{array}$ & $\begin{array}{l}0.15^{* *} \\
(0.01)\end{array}$ & $\begin{array}{l}0.15^{* *} \\
(0.01)\end{array}$ & $\begin{array}{l}0.15^{* *} \\
(0.01)\end{array}$ \\
\hline \multicolumn{2}{|l|}{$\mathrm{p}($ model $)$} & 0.01 & 0.01 & 0.01 & 0.01 \\
\hline \multicolumn{2}{|l|}{ Adjusted $R^{2}$} & 0.30 & 0.30 & 0.30 & 0.30 \\
\hline
\end{tabular}

See tables 2 and 3 for variable definitions. 
Table 5 (...continued)

Panel B: Tests of Hypotheses

\begin{tabular}{|c|c|c|c|c|c|}
\hline & $\begin{array}{c}\text { Model 1 } \\
\text { (p-values) }\end{array}$ & $\begin{array}{c}\text { Model 2 } \\
\text { (p-values) }\end{array}$ & $\begin{array}{c}\text { Model } 3 \\
\text { (p-values) }\end{array}$ & $\begin{array}{c}\text { Model } 4 \\
\text { (p-values) }\end{array}$ & $\begin{array}{c}\begin{array}{c}\text { Model } 4 \\
\text { (point } \\
\text { estimates }\end{array} \\
\end{array}$ \\
\hline \multicolumn{6}{|c|}{$\begin{array}{l}\text { Hypothesis H1 (Productivity of OLDSTAY versus } \\
\text { OLDQUTT or NEWQUTT after } 0,4 \text { or } 8 \text { quarters) }\end{array}$} \\
\hline $1.1 \quad \mathrm{p}\left(16 \eta^{\mathrm{OS}}=\lambda^{\mathrm{OQ}}+4 \eta^{\mathrm{OQ}}\right)$ & 0.01 & 0.01 & 0.01 & 0.01 & 11.09 \\
\hline $1.2 \mathrm{p}\left(16 \eta^{\mathrm{OS}}+4 \delta^{\mathrm{OS}}=\lambda^{\mathrm{OQ}}+4 \eta^{\mathrm{OQ}}+4 \delta^{\mathrm{OQ}}\right)$ & 0.01 & 0.01 & 0.01 & 0.01 & 15.01 \\
\hline $1.3 \mathrm{p}\left(16 \eta^{\mathrm{OS}}+8 \delta^{\mathrm{OS}}=\lambda^{\mathrm{OQ}}+4 \eta^{\mathrm{OQ}}+8 \delta^{\mathrm{OQ}}\right)$ & 0.01 & 0.01 & 0.01 & 0.01 & 18.93 \\
\hline $1.4 \mathrm{p}\left(16 \eta^{\mathrm{OS}}=\lambda^{\mathrm{NQ}}\right)$ & 0.01 & 0.01 & 0.01 & 0.01 & 12.84 \\
\hline $1.5 \mathrm{p}\left(16 \eta^{\mathrm{OS}}+4 \delta^{\mathrm{OS}}=\lambda^{\mathrm{NQ}}+4 \delta^{\mathrm{NQ}}\right)$ & 0.01 & 0.01 & 0.01 & 0.01 & 15.40 \\
\hline $1.6 \mathrm{p}\left(16 \eta^{\mathrm{OS}}+8 \delta^{\mathrm{OS}}=\lambda^{\mathrm{NQ}}+8 \delta^{\mathrm{NQ}}\right)$ & 0.01 & 0.01 & 0.01 & 0.01 & 17.96 \\
\hline \multicolumn{6}{|c|}{$\begin{array}{l}\text { Hypothesis H2 (Productivity of NEWSTAY versus } \\
\text { OLDQUTT or NEWQUTT after } 0,4 \text { or } 8 \text { quarters) }\end{array}$} \\
\hline $2.1 \quad \mathrm{p}\left(\lambda^{\mathrm{NS}}=\lambda^{\mathrm{OQ}}+4 \eta^{\mathrm{OQ}}\right)$ & 0.02 & 0.04 & 0.01 & 0.01 & 2.87 \\
\hline $2.2 \mathrm{p}\left(\lambda^{\mathrm{NS}}+4 \delta^{\mathrm{NS}}=\lambda^{\mathrm{OQ}}+4 \eta^{\mathrm{OQ}}+4 \delta^{\mathrm{OQ}}\right)$ & 0.01 & 0.01 & 0.01 & 0.01 & 10.11 \\
\hline $2.3 \mathrm{p}\left(\lambda^{\mathrm{NS}}+8 \delta^{\mathrm{NS}}=\lambda^{\mathrm{OQ}}+4 \eta^{\mathrm{OQ}}+8 \delta^{\mathrm{OQ}}\right)$ & 0.01 & 0.01 & 0.01 & 0.01 & 17.35 \\
\hline $2.4 \mathrm{p}\left(\lambda^{\mathrm{NS}}=\lambda^{\mathrm{NQ}}\right)$ & 0.01 & 0.01 & 0.01 & 0.01 & 4.62 \\
\hline $2.5 \mathrm{p}\left(\lambda^{\mathrm{NS}}+4 \delta^{\mathrm{NS}}=\lambda^{\mathrm{NQ}}+4 \delta^{\mathrm{NQ}}\right)$ & 0.01 & 0.01 & 0.01 & 0.01 & 10.50 \\
\hline $2.6 \mathrm{p}\left(\lambda^{\mathrm{NS}}+8 \delta^{\mathrm{NS}}=\lambda^{\mathrm{NQ}}+8 \delta^{\mathrm{NQ}}\right)$ & 0.01 & 0.01 & 0.01 & 0.01 & 16.38 \\
\hline \multicolumn{6}{|c|}{$\begin{array}{l}\text { Hypothesis H5 (Productivity growth rate of OLDSTAY } \\
\text { or NEWSTAY versus OLDQUIT or NEWQUTT) }\end{array}$} \\
\hline $5.1 \mathrm{p}\left(\delta^{\mathrm{OS}}=\delta^{\mathrm{OQ}}\right)$ & 0.01 & 0.01 & 0.01 & 0.01 & 0.98 \\
\hline $5.2 \mathrm{p}\left(\delta^{\mathrm{OS}}=\delta^{\mathrm{NQ}}\right)$ & 0.04 & 0.05 & 0.04 & 0.05 & 0.64 \\
\hline $5.3 \mathrm{p}\left(\delta^{\mathrm{NS}}=\delta^{\mathrm{OQ}}\right)$ & 0.01 & 0.01 & 0.01 & 0.01 & 1.81 \\
\hline $5.4 \mathrm{p}\left(\delta^{\mathrm{NS}}=\delta^{\mathrm{NQ}}\right)$ & 0.01 & 0.01 & 0.01 & 0.01 & 1.47 \\
\hline \multicolumn{6}{|c|}{$\begin{array}{l}\text { Hypothesis } \mathrm{H6} \text { (Productivity growth rates before and } \\
\text { after plan implementation) }\end{array}$} \\
\hline $6.1 p\left(\eta^{O S}=\delta^{O S}\right)$ & 0.01 & 0.10 & 0.01 & 0.10 & -0.16 \\
\hline $6.2 \mathrm{p}\left(\eta^{\mathrm{OQ}}=\delta^{\mathrm{OQ}}\right)$ & 0.02 & 0.02 & 0.01 & 0.01 & 0.78 \\
\hline \multicolumn{6}{|c|}{$\begin{array}{l}\text { OLDSTAY versus NEWSTAY (Productivity growth rate } \\
\text { and productivity after } 0,4 \text { or } 8 \text { quarters) }\end{array}$} \\
\hline $\mathrm{p}\left(\delta^{O S}=\delta^{N S}\right)$ & 0.01 & 0.01 & 0.01 & 0.01 & -0.83 \\
\hline $\mathrm{p}\left(16 \eta^{\mathrm{OS}}=\lambda^{\mathrm{NS}}\right)$ & 0.01 & 0.01 & 0.01 & 0.01 & 8.22 \\
\hline $\mathrm{p}\left(16 \eta^{\mathrm{OS}}+4 \delta^{\mathrm{OS}}=\lambda^{\mathrm{NS}}+4 \delta^{\mathrm{NS}}\right)$ & 0.01 & 0.01 & 0.01 & 0.01 & 4.80 \\
\hline $\mathrm{p}\left(16 \eta^{\mathrm{OS}}+8 \delta^{\mathrm{OS}}=\lambda^{\mathrm{NS}}+8 \delta^{\mathrm{NS}}\right)$ & 0.56 & 0.48 & 0.61 & 0.39 & 1.58 \\
\hline
\end{tabular}

(a) point estimates of the difference between the left and right hand sides of the hypothesis test,

Median of PRIORQTR for OLDQUTT $=4$,

Median of PRIORQTR for OLDSTAY $=16$,

GRWTHINDX $_{t}=$ Growth index, a control for changing economic conditions during the sample period. Model 1 does not have such a control. In model 2, GRWTHINDX $=$ a retail sales index published by Department of Labor Statistics. In model 3, GRWTHINDX = a sales growth index computed as the total quarterly sales for the 19 control stores that did not implement the plan. . In model 4, GRWTHINDX = a sales productivity index computed as the average quarterly sales per hour for the 19 control stores that did not implement the plan. 


\section{Table 6}

Selection Effect of Plan Implementation

( $p$-values in parentheses, $n=83$ store-quarters)

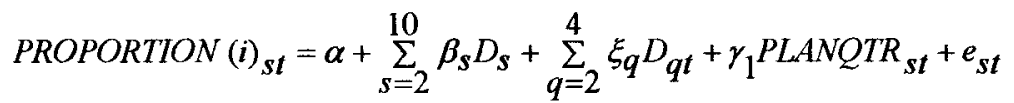

$$
\begin{aligned}
& \text { PROPORTION }(i)_{s t}=\alpha+\sum_{s=2}^{10} \beta_{s} D_{s}+\sum_{q=2}^{4} \xi_{q} D_{q t}+\gamma_{1} \text { PLANQTR }_{s t}+\gamma_{2} \text { PLANQTR }_{s t}^{2}+e_{s t}
\end{aligned}
$$

\begin{tabular}{|c|c|c|c|c|c|c|c|c|c|c|}
\hline $\begin{array}{c}\text { Variable } \\
\text { (parameter) }\end{array}$ & \multicolumn{2}{|c|}{ TEMPWORK } & \multicolumn{2}{|c|}{ NEWQUTT } & \multicolumn{2}{c|}{ NEWSTAY } & \multicolumn{2}{c|}{ OLDQUIT } & \multicolumn{2}{c|}{ OLDSTAY } \\
\hline $\begin{array}{c}\text { PLANQTR } \\
\left(\gamma_{1}\right)\end{array}$ & -0.07 & 0.20 & 0.60 & $9.83^{* *}$ & $3.86^{* *}$ & $3.27^{* *}$ & $-6.21^{* *}$ & $-13.83^{* *}$ & 0.06 & $3.48^{* *}$ \\
$(0.76)$ & $(0.83)$ & $(0.10)$ & $(0.01)$ & $(0.01)$ & $(0.01)$ & $(0.01)$ & $(0.01)$ & $(0.75)$ & $(0.01)$ \\
\hline $\begin{array}{c}\text { PLANQTR } \\
\left(\gamma_{2}\right)\end{array}$ & & -0.03 & & $-0.80^{* *}$ & & 0.05 & & $0.73^{* *}$ & & $-0.33^{* *}$ \\
$(0.01)$ & $(0.01)$ & & $(0.65)$ & & $0.01)$ \\
\hline Adj. $\mathrm{R}^{2}$ & 0.24 & 0.23 & 0.40 & 0.65 & 0.85 & 0.85 & 0.90 & 0.95 & 0.75 & 0.82 \\
\hline
\end{tabular}

PROPORTION(i) $)_{\text {st }}=$ Proportion of an employee type $\mathrm{i}$ in a store's workforce in a quarter, $\mathrm{i}=$ TEMPWORK, NEWQUIT, NEWSTAY, OLDQUIT, and OLDSTAY, PLANQTR = Number of quarters of a store under the incentive plan,

$D_{s}=$ a dummy variable to represent the store $s(=1 \ldots 10)$,

$\mathrm{D}_{\mathrm{qt}}=\mathrm{a}$ dummy variable to represent the fiscal quarter $\mathrm{q}(=1 \ldots 4)$,

$=1$ if the time period $\mathrm{t}$ is the same as fiscal quarter $\mathrm{q},=0$ otherwise,

$* *$ indicates significant at $1 \%$ level. 
Table 7

Regression Results for Random Effects Model with Quadratic Terms ( $p$-values in parentheses, $n=14,651$ employee-quarters)

$$
\begin{aligned}
& \text { HSALES } i t=\alpha+\sum_{s=2}^{10} \beta_{s} D_{s i}+\sum_{w=2}^{14} \gamma_{w} D_{w i}+\sum_{q=2}^{4} \xi_{q} D_{q t}+\zeta \text { GRWTHINDX }{ }_{t}+\lambda^{T P} D_{i}^{T P}+\lambda^{N Q} D_{i}^{N Q}+\lambda^{N S} D_{i}^{N S} \\
& +\lambda^{O Q} D_{i}^{O Q}+\delta^{N Q} D_{i}^{N Q} Q_{P L A N Q T R} i t+\delta^{N S} D_{i}^{N S} P_{\text {PLANQTR }} \text { it }+\delta \text { OQ } D_{i}^{O Q} \text { PLANQTR } i t \\
& +\delta \text { OS } D_{i}^{O S}{ }_{\text {PLANQTR }}{ }_{i t}+\theta^{N Q} D_{i}^{N Q}{ }_{\text {PLANQTR }}^{2}+\theta_{i t}^{N S} D_{i}^{N S} \text { PLANQTR }_{i t}^{2}+\theta^{O Q} D_{i}^{O Q} P_{\text {PLANQTR }}{ }_{i t}^{2}
\end{aligned}
$$

\begin{tabular}{|c|c|c|c|c|c|}
\hline Variable & Parameter & Model 1 & Model 2 & Model 3 & Model 4 \\
\hline $\mathrm{D}^{\mathrm{TP}}$ & $\lambda^{\mathrm{TP}}$ & $\begin{array}{l}-7.27^{* *} \\
(001)\end{array}$ & $\begin{array}{c}-7.78 * * \\
(001)\end{array}$ & $\begin{array}{l}-7.14^{* *} \\
(001)\end{array}$ & $-8.23^{* *}$ \\
\hline$D^{\mathrm{NQ}}$ & $\lambda^{\mathrm{NQ}}$ & $-10.77^{* *}$ & $-11.09^{* *}$ & $-10.71^{* *}$ & $-11.29^{* *}$ \\
\hline & & $(0.01)$ & $(0.01)$ & $(0.01)$ & $(0.01)$ \\
\hline $\mathrm{D}^{\mathrm{NS}}$ & $\lambda^{\mathrm{NS}}$ & $-5.15^{* *}$ & $-5.60^{* *}$ & $-5.04^{* *}$ & $-5.97^{* *}$ \\
\hline $\mathrm{D}^{\mathrm{OQ}}$ & $\lambda^{O Q}$ & $\begin{array}{l}(0.01) \\
-927^{* *}\end{array}$ & $\begin{array}{l}(0.01) \\
-917^{* *}\end{array}$ & $\begin{array}{l}(0.01) \\
-926 * *\end{array}$ & $(0.01)$ \\
\hline & & $(0.01)$ & $(0.01)$ & $(0.01)$ & $(0.01)$ \\
\hline $\mathbf{D}^{\mathrm{NQ}}$ PLANQTR & $\delta^{\mathrm{NQ}}$ & $1.91^{*}$ & $\begin{array}{l}1.86 \\
0.06)\end{array}$ & $1.96^{*}$ & $1.90^{*}$ \\
\hline $\mathrm{D}^{\mathrm{NQ}}$ PLANQTR $^{2}$ & $\theta^{\mathrm{NQ}}$ & $\begin{array}{l}-0.41^{*} \\
(0.02)\end{array}$ & $\begin{array}{l}-0.42^{*} \\
(0.02)\end{array}$ & $\begin{array}{l}-0.42^{*} \\
(0.02)\end{array}$ & $\begin{array}{l}-0.43^{* *} \\
(0.01)\end{array}$ \\
\hline $\mathrm{D}^{\mathrm{NS}}$ PLANQTR & $\delta^{\mathrm{NS}}$ & $\begin{array}{l}2.24^{* *} \\
(0.01)\end{array}$ & $\begin{array}{c}2.20^{* *} \\
(0.01)\end{array}$ & $\begin{array}{l}2.26^{* *} \\
(0.01)\end{array}$ & $\begin{array}{c}2.21 * * \\
(0.01)\end{array}$ \\
\hline $\mathbf{D}^{\mathrm{NS}}$ PLANQTR ${ }^{2}$ & $\theta^{\mathrm{NS}}$ & $\begin{array}{l}-0.16 \\
(0.12)\end{array}$ & $\begin{array}{l}-0.16 \\
(0.11)\end{array}$ & $\begin{array}{l}-0.16 \\
(0.12)\end{array}$ & $\begin{array}{l}-0.18 \\
(0.08)\end{array}$ \\
\hline $\mathrm{D}^{\mathrm{OQ}}$ PLANQTR & $\delta^{\mathrm{QQ}}$ & $\begin{array}{c}0.40 \\
(0.52)\end{array}$ & $\begin{array}{c}0.19 \\
(0.78)\end{array}$ & $\begin{array}{c}0.40 \\
(0.52)\end{array}$ & $\begin{array}{l}-0.03 \\
(0.96)\end{array}$ \\
\hline $\mathrm{D}^{\mathrm{OQ}}$ PLANQTR $^{2}$ & $\theta^{\mathrm{QQ}}$ & $\begin{array}{l}-0.13 \\
(0.14)\end{array}$ & $\begin{array}{l}-0.12 \\
(0.21)\end{array}$ & $\begin{array}{l}-0.13 \\
(0.15)\end{array}$ & $\begin{array}{l}-0.09 \\
(0.30)\end{array}$ \\
\hline $\mathrm{D}^{\mathrm{OS}}$ PLANQTR & $\delta^{\mathrm{os}}$ & $\begin{array}{l}1.00^{* *} \\
(0.01)\end{array}$ & $\begin{array}{r}0.88^{*} \\
(0.02)\end{array}$ & $\begin{array}{l}1.01^{* *} \\
(0.01)\end{array}$ & $\begin{array}{c}0.82^{*} \\
(0.02)\end{array}$ \\
\hline $\mathrm{D}^{\text {OS }}$ PLANQTR $^{2}$ & $\theta^{\text {OS }}$ & $\begin{array}{l}-0.06 \\
(0.13)\end{array}$ & $\begin{array}{l}-0.06 \\
(0.16)\end{array}$ & $\begin{array}{l}-0.06 \\
(0.14)\end{array}$ & $\begin{array}{l}-0.06 \\
(0.14)\end{array}$ \\
\hline $\mathrm{D}^{\text {QQPRIORQTR }}$ & $\eta^{Q Q}$ & $\begin{array}{c}0.11^{*} \\
(0.02)\end{array}$ & $\begin{array}{c}0.11^{*} \\
(0.02)\end{array}$ & $\begin{array}{c}0.11^{*} \\
(0.02)\end{array}$ & $\begin{array}{c}0.11^{*} \\
(0.02)\end{array}$ \\
\hline $\mathbf{D}^{\text {OS}}$ PRIORQTR & $\eta^{\text {os }}$ & $\begin{array}{c}0.15^{* *} \\
(0.01)\end{array}$ & $\begin{array}{c}0.15^{* *} \\
(0.01)\end{array}$ & $\begin{array}{c}0.15^{* *} \\
(0.01)\end{array}$ & $\begin{array}{c}0.15^{* *} \\
(0.01)\end{array}$ \\
\hline p(model) & & 0.01 & 0.01 & 0.01 & 0.01 \\
\hline Adjusted $\mathbf{R}^{2}$ & & 0.31 & 0.31 & 0.31 & 0.31 \\
\hline
\end{tabular}

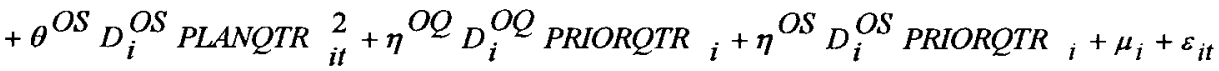

Panel A: Parameter Estimates

** indicates significant at $1 \%$ level,

* indicates significant at $5 \%$ level,

See tables 2 and 3 for variable definitions. 
Table 7(...continued)

Panel B: Tests of Hypotheses

\begin{tabular}{|c|c|c|c|c|c|}
\hline & $\begin{array}{c}\text { Model } 1 \\
\text { (p-values) }\end{array}$ & $\begin{array}{c}\text { Model } 2 \\
\text { (p-values) }\end{array}$ & $\begin{array}{c}\text { Model } 3 \\
\text { (p-values) }\end{array}$ & $\begin{array}{c}\text { Model } 4 \\
\text { (p-values) }\end{array}$ & $\begin{array}{c}\text { Model } 4 \\
\text { (point } \\
\text { estimates) }^{@} \\
\end{array}$ \\
\hline \multicolumn{6}{|l|}{$\begin{array}{l}\text { Hypothesis H1 (Productivity of OLDSTAY versus OLDQUTT } \\
\text { or NEWQUTT after } 0,4 \text { or } 8 \text { quarters) }\end{array}$} \\
\hline $1.1 \quad \mathrm{p}\left(16 \eta^{\mathrm{OS}}=\lambda^{\mathrm{OQ}}+4 \eta^{\mathrm{OQ}}\right)$ & 0.01 & 0.01 & 0.01 & 0.01 & 10.99 \\
\hline $1.2 \mathrm{p}\left(16 \eta^{\mathrm{OS}}+4 \delta^{\mathrm{OS}}+16 \theta^{\mathrm{OS}}=\lambda^{\mathrm{OQ}}+4 \eta^{\mathrm{OQ}}+4 \delta^{\mathrm{OQ}}+16 \theta^{\mathrm{OQ}}\right)$ & 0.01 & 0.01 & 0.01 & 0.01 & 14.87 \\
\hline $1.3 \mathrm{p}\left(16 \eta^{\mathrm{OS}}+8 \delta^{\mathrm{OS}}+64 \theta^{\mathrm{OS}}=\lambda^{\mathrm{OQ}}+4 \eta^{\mathrm{OQ}}+8 \delta^{\mathrm{OQ}}+64 \theta^{\mathrm{OQ}}\right)$ & 0.01 & 0.01 & 0.01 & 0.01 & 19.71 \\
\hline $1.4 \mathrm{p}\left(16 \eta^{\mathrm{OS}}=\lambda^{\mathrm{NQ}}\right)$ & 0.01 & 0.01 & 0.01 & 0.01 & 13.69 \\
\hline $1.5 \mathrm{p}\left(16 \eta^{\mathrm{OS}}+4 \delta^{\mathrm{OS}}+16 \theta^{\mathrm{OS}}=\lambda^{\mathrm{NQ}}+4 \delta^{\mathrm{NQ}}+16 \theta^{\mathrm{NQ}}\right)$ & 0.01 & 0.01 & 0.01 & 0.01 & 15.29 \\
\hline $1.6 \mathrm{p}\left(16 \eta^{\mathrm{OS}}+8 \delta^{\mathrm{OS}}+64 \theta^{\mathrm{OS}}=\lambda^{\mathrm{NQ}}+8 \delta^{\mathrm{NQ}}+64 \theta^{\mathrm{NQ}}\right)$ & 0.01 & 0.01 & 0.01 & 0.01 & 28.73 \\
\hline \multicolumn{6}{|l|}{$\begin{array}{c}\text { Hypothesis H2 (Productivity of NEWSTAY versus OLDQUTT } \\
\text { or NEWQUT after } 0,4 \text { or } 8 \text { quarters) }\end{array}$} \\
\hline $2.1 \mathrm{p}\left(\lambda^{\mathrm{NS}}=\lambda^{\mathrm{OQ}}+4 \eta^{\mathrm{OQ}}\right)$ & 0.01 & 0.04 & 0.01 & 0.05 & 2.62 \\
\hline $2.2 \mathrm{p}\left(\lambda^{\mathrm{NS}}+4 \delta^{\mathrm{NS}}+16 \theta^{\mathrm{NS}}=\lambda^{\mathrm{OQ}}+4 \eta^{\mathrm{OQ}}+4 \delta^{\mathrm{OQ}}+16 \theta^{\mathrm{OQ}}\right)$ & 0.01 & 0.01 & 0.01 & 0.01 & 10.14 \\
\hline $2.3 \mathrm{p}\left(\lambda^{\mathrm{NS}}+8 \delta^{\mathrm{NS}}+64 \theta^{\mathrm{NS}}=\lambda^{\mathrm{OQ}}+4 \eta^{\mathrm{OQ}}+8 \delta^{\mathrm{OQ}}+64 \theta^{\mathrm{OQ}}\right)$ & 0.01 & 0.01 & 0.01 & 0.01 & 14.78 \\
\hline $2.4 \mathrm{p}\left(\lambda^{\mathrm{NS}}=\lambda^{\mathrm{NQ}}\right)$ & 0.01 & 0.01 & 0.01 & 0.01 & 5.32 \\
\hline $2.5 \mathrm{p}\left(\lambda^{\mathrm{NS}}+4 \delta^{\mathrm{NS}}+16 \theta^{\mathrm{NS}}=\lambda^{\mathrm{NQ}}+4 \delta^{\mathrm{NQ}}+16 \theta^{\mathrm{NQ}}\right)$ & 0.01 & 0.01 & 0.01 & 0.01 & 10.58 \\
\hline $2.6 \mathrm{p}\left(\lambda^{\mathrm{NS}}+8 \delta^{\mathrm{NS}}+64 \theta^{\mathrm{NS}}=\lambda^{\mathrm{NQ}}+8 \delta^{\mathrm{NQ}}+64 \theta^{\mathrm{NQ}}\right)$ & 0.01 & 0.01 & 0.01 & 0.01 & 23.80 \\
\hline \multicolumn{6}{|l|}{$\begin{array}{l}\text { Hypothesis H4 (Productivity growth rates for OLDSTAY and } \\
\text { NEWSTAY) }\end{array}$} \\
\hline $4.1 \mathrm{p}\left(\delta^{\mathrm{os}}+6 \theta^{\mathrm{os}}=0\right)$ & 0.01 & 0.01 & 0.01 & 0.01 & 0.46 \\
\hline $4.2 \mathrm{p}\left(\delta^{\mathrm{NS}}+6 \theta^{\mathrm{NS}}=0\right)$ & 0.01 & 0.01 & 0.01 & 0.01 & 1.13 \\
\hline \multicolumn{6}{|l|}{$\begin{array}{c}\text { Hypothesis H5 (Productivity growth rate of OLDSTAY or } \\
\text { NEWSTAY versus OLDQUTT or NEWQUTT) }\end{array}$} \\
\hline $5.1 \mathrm{p}\left(\delta^{\mathrm{OS}}+6 \theta^{\mathrm{OS}}=\delta^{\mathrm{OQ}}+6 \theta^{\mathrm{OQ}}\right)$ & 0.01 & 0.01 & 0.01 & 0.01 & 1.03 \\
\hline $5.2 \mathrm{p}\left(\delta^{\mathrm{OS}}+6 \theta^{\mathrm{OS}}=\delta^{\mathrm{NQ}}+6 \theta^{\mathrm{NQ}}\right)$ & 0.01 & 0.02 & 0.02 & 0.01 & 1.14 \\
\hline $5.3 \mathrm{p}\left(\delta^{\mathrm{NS}}+6 \theta^{\mathrm{NS}}=\delta^{\mathrm{OQ}}+6 \theta^{\mathrm{OQ}}\right)$ & 0.01 & 0.01 & 0.01 & 0.01 & 1.70 \\
\hline $5.4 \quad \mathrm{p}\left(\delta^{\mathrm{NS}}+6 \theta^{\mathrm{NS}}=\delta^{\mathrm{NQ}}+6 \theta^{\mathrm{NQ}}\right)$ & 0.01 & 0.01 & 0.01 & 0.01 & 1.81 \\
\hline \multicolumn{6}{|l|}{$\begin{array}{l}\text { Hypothesis H6 (Productivity growth rates before and after plan } \\
\text { implementation) }\end{array}$} \\
\hline $6.1 \mathrm{p}\left(\eta^{\mathrm{os}}=\delta^{\mathrm{os}}+6 \theta^{\mathrm{os}}\right)$ & 0.01 & 0.04 & 0.01 & 0.06 & -0.31 \\
\hline $6.2 \mathrm{p}\left(\eta^{\mathrm{OQ}}=\delta^{\mathrm{OQ}}+6 \theta^{\mathrm{OQ}}\right)$ & 0.05 & 0.05 & 0.06 & 0.01 & 0.68 \\
\hline \multicolumn{6}{|l|}{$\begin{array}{l}\text { OLDSTAY versus NEWSTAY (Productivity growth rate and } \\
\text { productivity after } 0,4 \text { or } 8 \text { quarters) }\end{array}$} \\
\hline $\mathrm{p}\left(\delta^{\mathrm{OS}}+6 \theta^{\mathrm{OS}}=\delta^{\mathrm{NS}}+6 \theta^{\mathrm{NS}}\right)$ & 0.01 & 0.02 & 0.03 & 0.02 & -0.67 \\
\hline $\mathrm{p}\left(16 \eta^{\mathrm{OS}}=\lambda^{\mathrm{NS}}\right)$ & 0.01 & 0.01 & 0.01 & 0.01 & 8.37 \\
\hline $\mathrm{p}\left(16 \eta^{\mathrm{OS}}+4 \delta^{\mathrm{OS}}+16 \theta^{\mathrm{OS}}=\lambda^{\mathrm{NS}}+4 \delta^{\mathrm{NS}}+16 \theta^{\mathrm{NS}}\right)$ & 0.01 & 0.01 & 0.01 & 0.01 & 4.73 \\
\hline $\mathrm{p}\left(16 \eta^{\mathrm{OS}}+8 \delta^{\mathrm{OS}}+64 \theta^{\mathrm{OS}}=\lambda^{\mathrm{NS}}+8 \delta^{\mathrm{NS}}+64 \theta^{\mathrm{NS}}\right)$ & 0.18 & 0.16 & 0.19 & 0.08 & 4.93 \\
\hline
\end{tabular}

a point estimates of the difference between the left and right hand sides of the hypothesis test. See table 5 - panel $\mathrm{B}$ for variable definitions. Median of PRIORQTR for OLDQUTT $=4$. Median of PRIORQTR for OLDSTAY =16. Median of PLANQTR=3.

Productivity growth rate: For the quadratic model, the productivity growth rate is given by $\delta+2$ PLANQTR* $\theta$. Hypothesis tests reported above are evaluated at the median value of PLANQTR $=3$ so that the productivity growth rate is given by $\delta_{i}+6 \theta_{i}$ for each employee type $i$. 
Figure 1

Plot of Average Incremental Sales Around Date of Implementation of

Plan

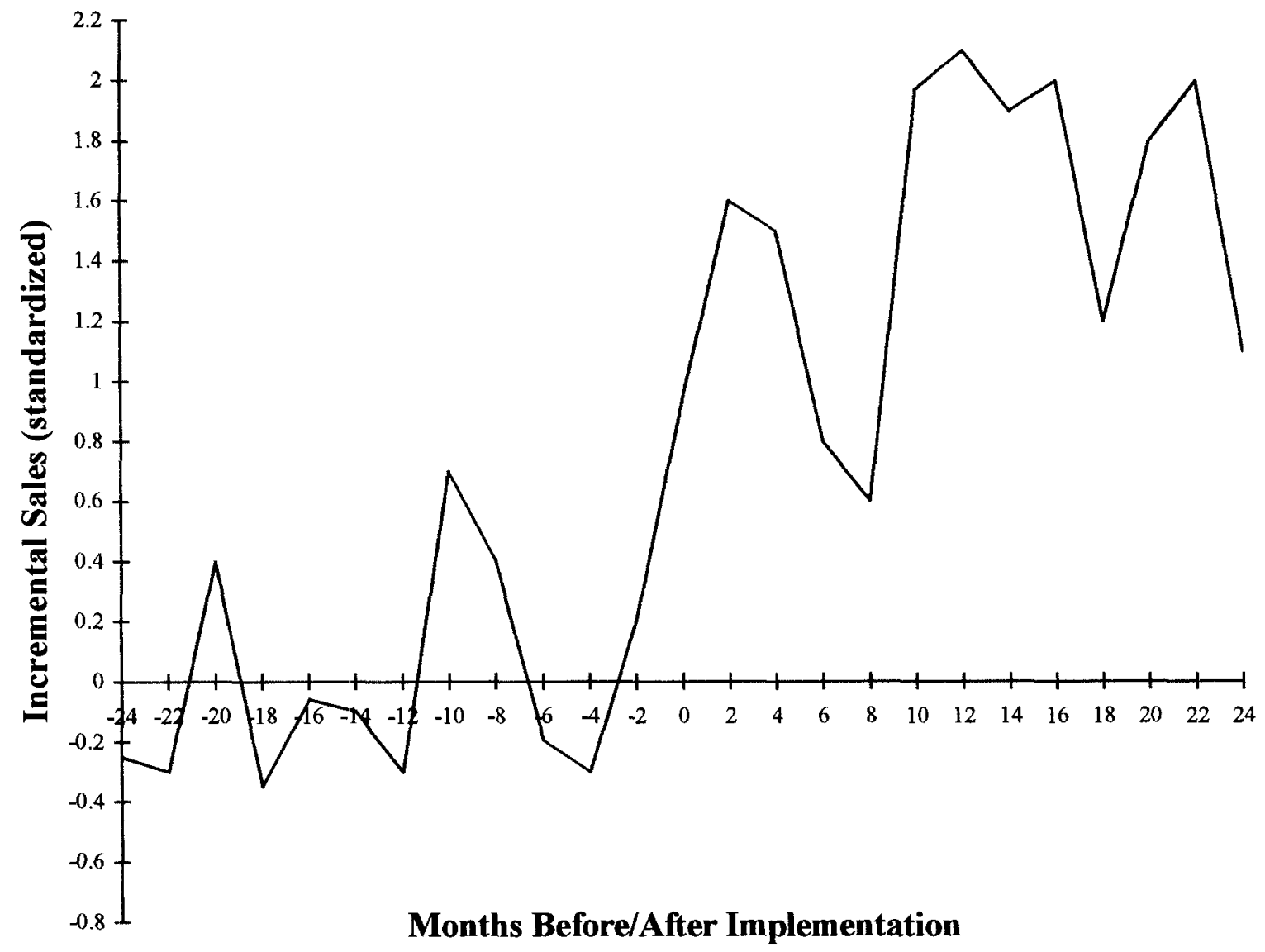

Model: SALES $_{s t}=\alpha_{s}+\beta_{s}$ AVGCOSAL $_{t}+\varepsilon_{s t}$ for each $s=1, \ldots 15$,

where

SALES $_{\mathrm{st}}=$ Sales of store $\mathrm{s}$ in month $\mathbf{t}$

AVGCOSAL ${ }_{t}=$ Average monthly sales of the 19 company stores in the same geographic region that did not implement the incentive plan, and

$\hat{\alpha}_{\mathrm{S}}$ and $\hat{\beta}_{\mathrm{S}}$ are estimated using monthly data for 24 months prior to the plan implementation.

Incremental Sales $_{s t}($ standardized $)=\sum_{s=1}^{15}\left(\operatorname{SALES}_{\mathrm{st}}-\hat{\alpha}_{\mathrm{s}}-\hat{\boldsymbol{\beta}}_{\mathrm{s}} \mathrm{AVGCOSAL}_{\mathrm{t}}\right) / 15 \sqrt{\operatorname{Var}\left(\varepsilon_{\mathrm{st}}\right)}$

For $\mathrm{t}=-24, \ldots-1,0, \ldots 24$, where $\mathrm{t}=0$ is the month of plan implementation.

Source: Banker, Lee and Potter. Journal of Accounting and Economics 21 (1996, p.212). 


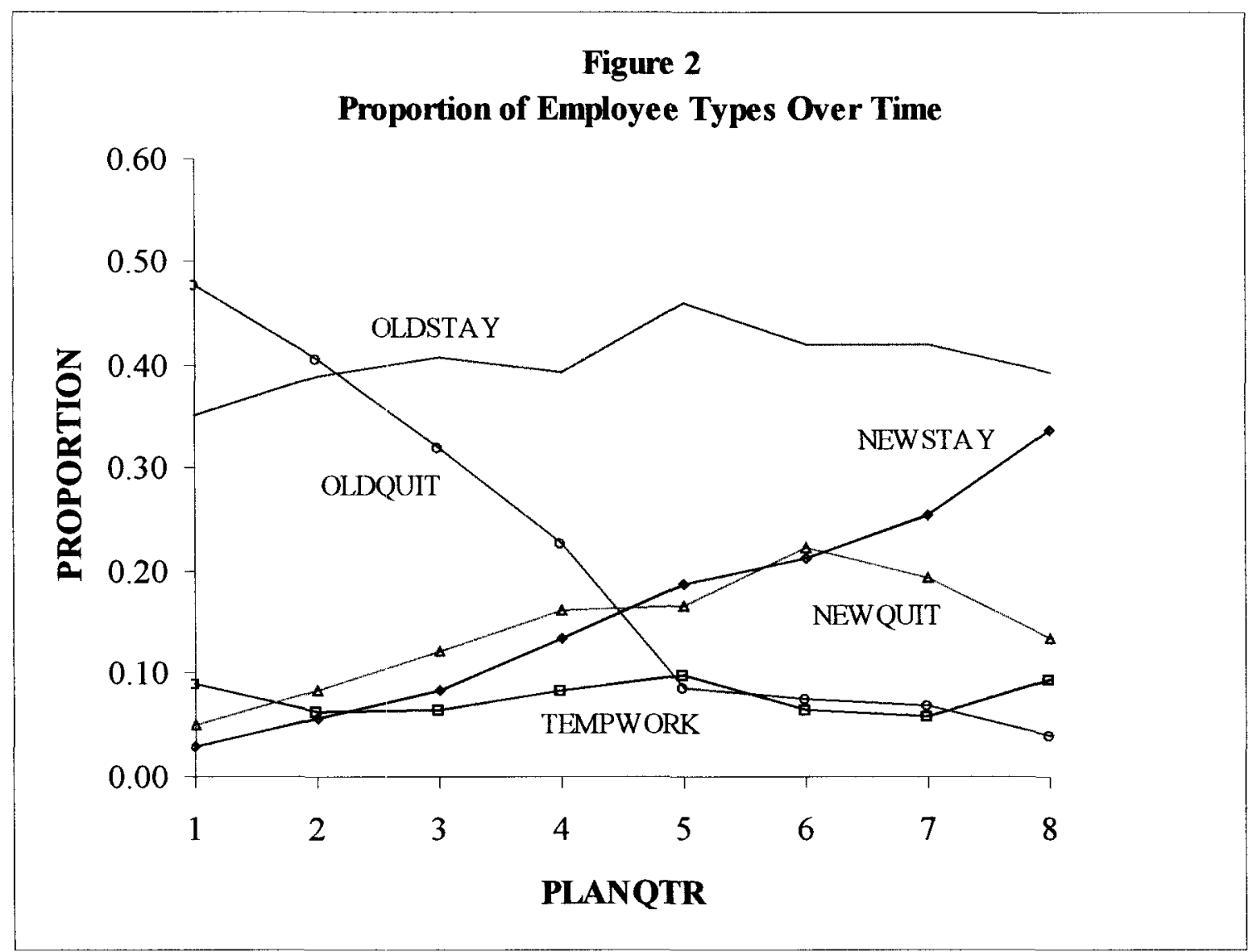

TEMPWORK = An employee who remains with the store for no more than two quarters during the sample period, NEWQUTT = An employee who joins the store after incentive plan implementation and who leaves the store prior to the end of our sample period,

NEWSTAY = An employee who joins the store after incentive plan implementation and who remains until the end of our sample period,

OLDQUIT = An employee who is vith the store before plan implementation and who leaves prior to the end of our sample period,

OLDSTAY = An employee who is with the store before plan implementation and who remains until the end of our sample period,

PLANQTR = Number of quarters of a store under the plan,

PROPORTION = Proportion of an employee type in a store's workforce in a quarter. 


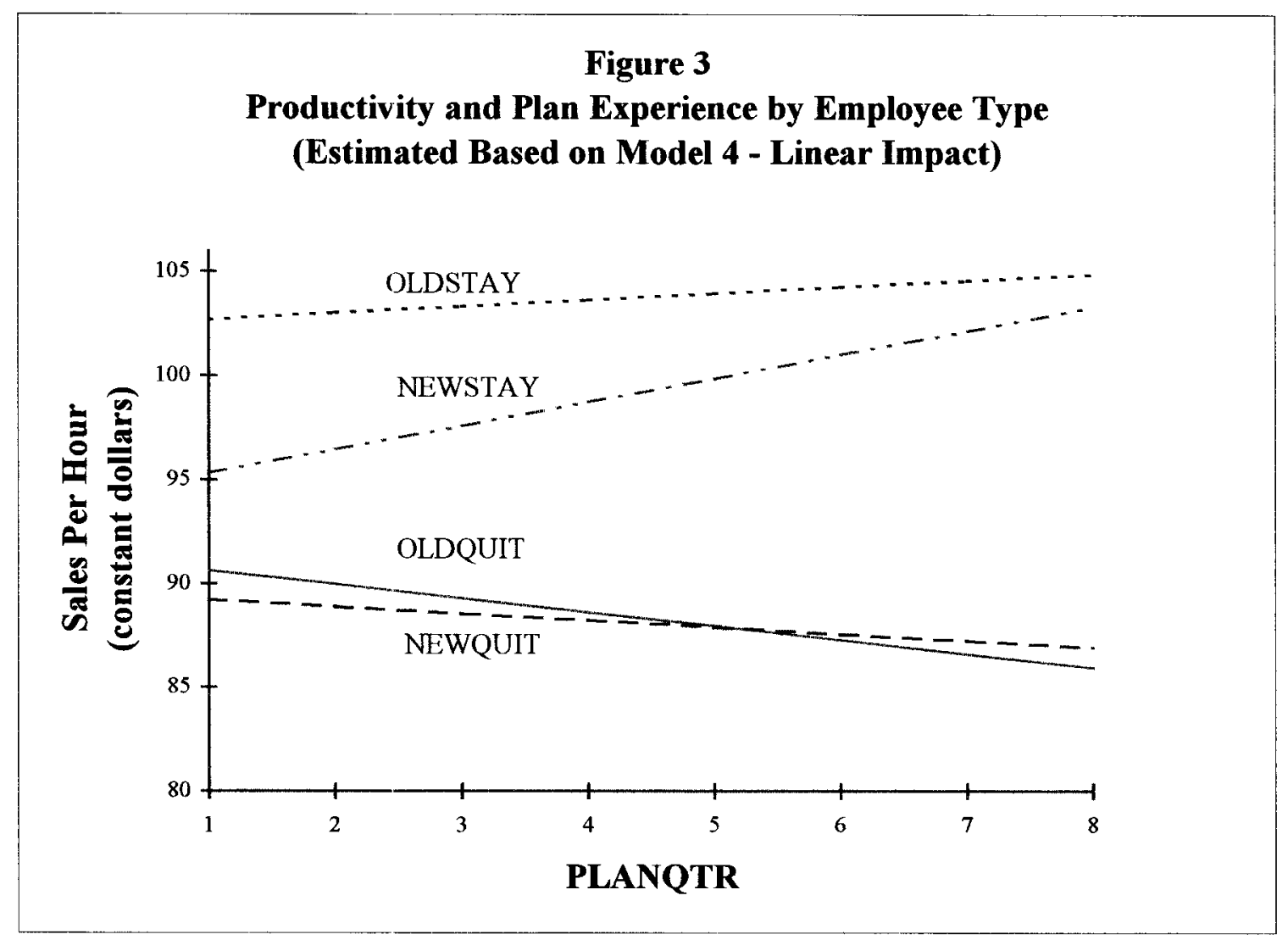

TEMPWORK = An employee who remains with the store for no more than two quarters during the sample period, NEWQUTT = An employee who joins the store after incentive plan implementation and who leaves the store prior to the end of our sample period,

NEWSTAY $=$ An employee who joins the store after incentive plan implementation and who remains until the end of our sample period,

OLDQUTT = An employee who is with the store before plan implementation and who leaves prior to the end of our sample period,

OLDSTAY = An employee who is with the store before plan implementation and who remains until the end of our sample period,

PLANQTR = Number of quarters of service by an employee under the plan,

Sales Per Hour $=$ Average sales per hour (in constant dollars) for employee type $\mathrm{i}$ in a quarter. 


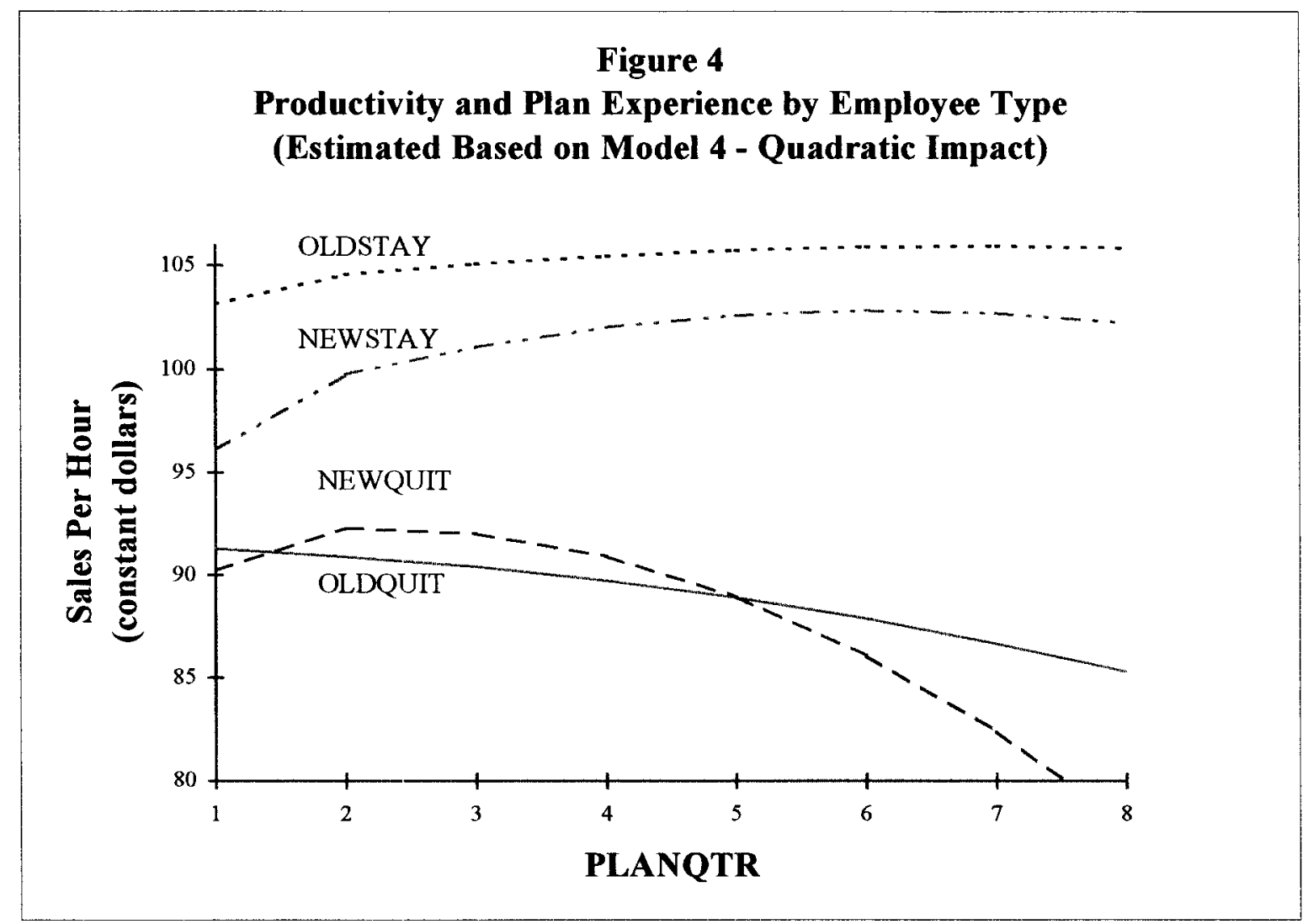

TEMPWORK = An employee who remains with the store for no more than two quarters during the sample period, NEWQUIT = An employee who joins the store after incentive plan implementation and who leaves the store prior to the end of our sample period,

NEWSTAY = An employee who joins the store after incentive plan implementation and who remains until the end of our sample period,

OLDQUIT = An employee who is with the store before plan implementation and who leaves prior to the end of our sample period,

OLDSTAY = An employee who is with the store before plan implementation and who remains until the end of our sample period,

PLANQTR = Number of quarters of service by an employee under the plan,

Sales Per Hour $=$ Average sales per hour (in constant dollars) for employee type $i$ in a quarter. 


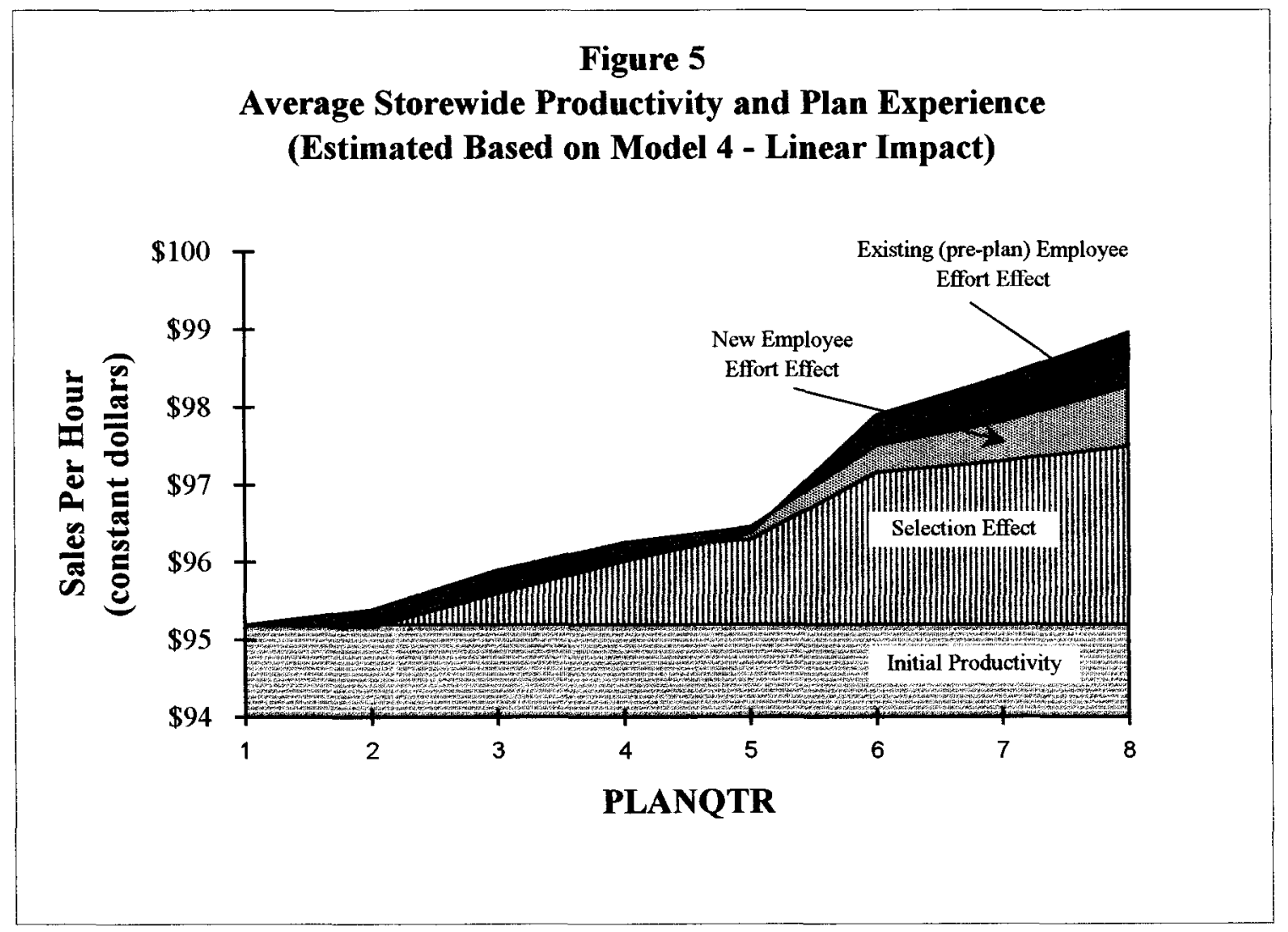

PLANQTR $=$ Number of quarters of a store under the plan,

Sales Per Hour $=$ Average storewide sales per hour (in constant dollars) in a quarter. 